\title{
Reactive oxygen species induced by icaritin promote DNA strand breaks and apoptosis in human cervical cancer cells
}

\author{
$\mathrm{XIN} \mathrm{CHEN}^{1}, \mathrm{LIYAN} \mathrm{SONG}^{2}, \mathrm{YUEFANG} \mathrm{HOU}^{2}$ and FAN LI ${ }^{1}$ \\ ${ }^{1}$ Department of Pathogenobiology, The Key Laboratory of Zoonosis, Chinese Ministry of Education, \\ College of Basic Medicine, Jilin University, Changchun, Jilin 130021; ${ }^{2}$ School of Life Sciences, \\ Jilin University, Changchun, Jilin 130012, P.R. China
}

Received March 17, 2018; Accepted October 8, 2018

DOI: $10.3892 /$ or.2018.6864

\begin{abstract}
Increased production of reactive oxygen species (ROS) is a distinct feature of various types of cancer. ROS drive tumor progression and render cancer cells vulnerable to additional oxidative insult. The various natural herb compounds have been shown to induce additional production of ROS in cancer cells, although the physiological implications of ROS under these conditions are not fully determined. In the present study, icaritin, a natural compound derived from the medicinal plants Epimedium, was demonstrated to potently suppresses the proliferation of human HeLa and SiHa cervical cancer cells, without similar affects on non-cancerous CCD-1095Sk fibroblasts and 293 cells, as measured by MTT and colony formation assays. Icaritin treatment caused a rapid increase in ROS in HeLa and SiHa cells, which was followed by a prominent increase in the number of DNA strand breaks. Consequently, the levels of the pro-apoptotic protein Bax and activated caspase 3 and 9 enzymes were increased, while the levels of the anti-apoptotic proteins Bcl-2 and XIAP were downregulated. These protein expression changes were accompanied by marked induction of apoptosis in icaritin-treated cancer cells. The results suggested that the icaritin-induced ROS overload promoted cancer cell death via induction of extensive oxidative DNA damage, which subsequently resulted in large numbers of DNA strand breaks and the activation of the intrinsic apoptotic pathway.
\end{abstract}

Correspondence to: Professor Fan Li, Department of Pathogenobiology, The Key Laboratory of Zoonosis, Chinese Ministry of Education, College of Basic Medicine, Jilin University, 828 Xinmin Street, Changchun, Jilin 130021, P.R. China

E-mail: lifan@jlu.edu.cn

Key words: icaritin, reactive oxygen species, DNA damage, DNA double strand break, apoptosis, cervical cancer

\section{Introduction}

Traditional anticancer therapies target both cancer and normal cells indiscriminately, and are often ineffective in the treatment of relapsed tumors. Consequently, a major aim of cancer drug development is to target cancer-specific genetic alterations or signaling pathways. This strategy has lead to the identification and development of some highly effective and less toxic drugs, including small molecules and antibodies (1). However, such targeted drugs are limited by the diversity of cancer genotypes and intratumor heterogeneity, as well as the rapid development of drug resistance $(2,3)$. Thus, there is still an ongoing and urgent need for the design of novel agents that can effectively target cancer cells with broad-spectrum efficacy, while leaving normal cells less affected. To this end, targeting cancer-specific biochemical pathways that are crucial for the survival of malignant cells and dispensable for normal cells are likely to be some of the most promising anticancer strategies (4-6).

Increased production of reactive oxygen species (ROS) is a distinct feature of various types of cancer (7). Intracellular ROS have been linked to a myriad of physiological activities and pathological changes. Although ROS can activate signaling pathways that regulate normal and cancer cellular proliferation and growth, elevated ROS levels denote oxidative stress that can damage cellular components and jeopardize cell survival (8). In order to survive, cancer cells rewire biochemical pathways to antagonize the toxicity of increased ROS and enhance the function of repair systems to withstand the resultant oxidative damage (9). However, adaptation to the intense oxidative pressure by cancer cells creates cancer-specific conditions that are vulnerable to disruptions of the rewired biochemical pathways (10). Thus, further ROS insult, reductions in the antioxidants levels, and/or blockage of damage repair pathways during the malignant transformation of cancer genotypes may result in artificial lethality and selective killing of cancer cells (4).

Icaritin is a natural compound derived from the medicinal plants of the Epimedium family (11). Crude extracts of Epimedium plants have been used in traditional Chinese herbal formulations to treat bone, neural, cardiovascular and 
immune malfunctions and/or are administered as aphrodisiacs for their sexual performance-enhancing properties (12). The major bioactive herbal ingredient of Epimedium plants has been identified to be icariin, together with smaller amounts of icaritin, desmethylicaritin, icariside I and icariside II (13). In addition to the natural constituents of Epimedium plants, icaritin, desmethylicaritin, icariside I and icariside II are also generated from icariin through deglycosylation and demethylation by intestinal microflora (13). These Epimedium prenylflavonoids are structurally similar and functionally related to estrogen and are, hence, called phytoestrogens (14).

Depending on the working compound concentration and cellular context, icaritin has demonstrated both agonistic and antagonistic activities towards the various types of estrogen receptors (ERs). By acting as an agonist of the canonical ERs (ER $\alpha$ and $E R \beta)$, icaritin promotes repair of bone and cardiovascular damage by inducing osteogenic and cardiomyogenic differentiation $(12,15)$. Similarly, icaritin stimulates mammary epithelial cell proliferation (14) and stem cell self-renewal (16), while it inhibits neuronal apoptosis and hence acts in a neuroprotective manner in certain neurodegenerative models (17). In addition to the canonical ERs, icaritin may also activate the membrane-bound G-protein ER 1 to promote proliferation of some ER-negative breast cancers (18). However, most ER-negative breast cancers, as well as some BCR, RhoGEF and GTPase activating protein (BCR)-ABL proto-oncogene 1, non-receptor tyrosine kinase $(\mathrm{ABL})^{+}$leukemic cells, overexpress the ER $\alpha$ variant $E R \alpha-36$, and are therefore suppressed by icaritin, whose action blocks ER $\alpha$-36-mediated epidermal growth factor receptor-Src-extracellular signal-regulated kinase (ERK) and/or BCR-ABL-mediated growth factor receptor-bound protein 2-Ras signaling (19-23). Moreover, icaritin binds to the aryl hydrocarbon receptor in order to promote degradation of ER $\alpha$ and/or androgen receptor (AR); whereas, it further suppresses ER $\alpha$-positive breast cancer and AR-positive prostate cancer $(24,25)$.

In addition to the phytoestrogen-associated cytotoxicity against breast and prostate cancer, icaritin has also demonstrated potent toxicity against broader types of cancer, which is independent of the expression of ER and AR $(11,26)$. The majority of the studies indicated that icaritin induces cell cycle arrest and apoptosis or autophagic cell death in various types of cancer, by distinct mechanisms of action, including suppression of interleukin (IL)-6/Janus kinase 2 (Jak2)/signal transducer and activator of transcription 3 (STAT3) and/or mitogen-activated protein kinase (MAPK) signaling (27-30), sustained activation of ERK1/2 or c-Jun N-terminal kinase (JNK1) $(26,31,32)$, inhibition of phosphatidylinositol 3-kinase (PI3K)/RAC- $\alpha$ serine/threonine-protein kinase (Akt) pathway (33) and 5'-AMP-activated protein kinase (AMPK)-dependent inhibition of serine/threonine-protein kinase mTOR (34). However, the molecular mechanisms that link icaritin to these signaling pathways remain undiscovered. Icaritin has been shown to stimulate ROS generation in certain types of cells (34-38). However, it is not known whether ROS play a role in the anticancer toxicity of icaritin. Although, cervical cancer is among the top 10 cancers in incidence and mortality globally (39), the effect of icaritin on cervical cancer has not been examined. In the present study, it was demonstrated that icaritin treatment caused a rapid increase in ROS in the human HeLa and SiHa cervical cancer cell lines, which subsequently resulted in extensive oxidative DNA damage and large numbers of DNA breaks, and eventually caused activation of the intrinsic apoptosis pathway. These results suggest that icaritin can cause cancer cell death via the induction of the DNA damage response (DDR)-triggered cell death. Thus, icaritin may be an optimal drug candidate for the treatment of cervical cancer.

\section{Materials and methods}

Cells and reagents. The human HeLa and SiHa cervical cancer cell lines, and the non-cancerous 293 and CCD-1095Sk cell lines were purchased from the American Type Culture Collection (ATCC; Manassas, VA, USA). The cells were cultured in $37^{\circ} \mathrm{C}$ with $5 \% \mathrm{CO}_{2}$ according to the instructions provided by ATCC. Icaritin was purchased from Yuanye Biotechnology (Shanghai, China). The purity was measured by high-performance liquid chromatography (15) and determined to be $99.6 \%$. Stock solutions of icaritin were prepared in $100 \%$ dimethyl sulfoxide (DMSO; Sigma-Aldrich; Merck KGaA, Darmstadt, Germany), and working solutions were in complete cell culture medium. Vehicle control samples included the same amount of DMSO in the absence of icaritin. $\mathrm{N}$-acetyl cysteine (NAC) was purchased from Calbiochem (EMD Millipore, Billerica, MA, USA). The sources of additional reagents were specified in the relevant sections.

MTT assay. The cells were seeded in 96-well plates at a density of 2,000 cells per well for $12 \mathrm{~h}$, and then treated with icaritin or vehicle control for 24 or $48 \mathrm{~h}$. A total of $20 \mu \mathrm{l} \mathrm{MTT}$ (Invitrogen; Thermo Fisher Scientific, Inc., Waltham, MA, USA) solution ( $5 \mathrm{mg} / \mathrm{ml}$ in PBS) was added to each well. The plate was incubated at $37^{\circ} \mathrm{C}$ for an additional $4 \mathrm{~h}$. Following removal of the culture medium, the cells were incubated in $150 \mu 1100 \%$ DMSO on a plate shaker for $10 \mathrm{~min}$. The absorbance was measured at $595 \mathrm{~nm}$ was measured by a microplate reader (Bio-Rad Laboratories, Inc., Hercules, CA, USA). The data were analyzed using the GraphPad Prism software (GraphPad Software, Inc., La Jolla, CA, USA).

Colony formation assay. The cells were seeded in 6-well plates at 2,000 cells/well for $12 \mathrm{~h}$ and then treated with different concentrations of icaritin or vehicle control for 8 days. Following washing with PBS, the cells were fixed in ice-cold methanol and briefly stained with crystal violet solution $(0.5 \%$ in 25\% methanol; Sigma-Aldrich; Merck KGaA). The plates were air-dried overnight and photographs were captured with a Canon digital camera (PowerShot ELPH 180 20-Megapixel; Canon, Inc., Tokyo, Japan). Ethanol (70\%) was added to dissolve the violet crystals and the absorbance at $595 \mathrm{~nm}$ was measured by a microplate reader (Bio-Rad Laboratories, Inc.). The data were analyzed using the GraphPad Prism software.

Wound healing assay. The cells were seeded in 12-well plates at a density of $3 \times 10^{5}$ cells/well until they reached $70-80 \%$ confluence as a monolayer. A vertical straight scratch across the center of each well was made by gently and slowly scratching the monolayer with a $1 \mathrm{ml}$ pipette tip in one direction. The wells were washed twice with medium to 
remove the detached cells and fresh medium was added that contained different concentrations of icaritin and/or vehicle control. phase-contrast microscopy images were captured at 0,24 and $48 \mathrm{~h}$ and analyzed using the Image J software (National Institutes of Health, Bethesda, MA, USA).

ROS measurement. Total cellular ROS were measured by flow cytometry using a cell-based ROS assay kit (Beyotime Institute of Biotechnology, Haimen, China). Following drug treatment, the cells were washed twice with PBS and subsequently incubated with $10 \mu \mathrm{M}$ dichlorofluorescin diacetate (DCFH-DA) at $37^{\circ} \mathrm{C}$ for $30 \mathrm{~min}$ in the dark. The cells were collected following trypsin digestion (Thermo Fisher Scientific, Inc.) and then analyzed by the FACSCaliber flow cytometer (BD Biosciences, San Jose, CA, USA). Total cellular ROS levels were expressed as the averaged DCF fluorescence intensity of the cells. The data presented is average of three independent experiments.

Immunofluorescent staining. Following drug treatment, the cells were washed once by PBS, fixed in methanol/acetone $(\mathrm{v} / \mathrm{v}, 1 / 1)$ at $4^{\circ} \mathrm{C}$ for $15 \mathrm{~min}$, and washed 3 times with PBS. Fixed cells were blocked in $0.3 \%$ Triton X-100 with $1.5 \%$ bovine serum albumin (BSA) at room temperature for $30 \mathrm{~min}$, incubated with rabbit-anti-TP53-binding protein 1 (53BP1; 1:1,000; cat. no. A300-272A; Bethyl Laboratories, Inc., Montgomery, TX, USA) and/or rabbit-anti- $\gamma \mathrm{H} 2 \mathrm{AX}$ histone (1:500; cat. no. bs-3185R; BIOSS, Beijing, China) primary antibodies at $4^{\circ} \mathrm{C}$ overnight, followed by incubation with Cy3-conjugated goat-anti-rabbit (1:250; cat. no. 111-165-003; Jackson ImmunoResearch Laboratories, Inc., West Grove, PA, USA) secondary antibody for $1 \mathrm{~h}$ at room temperature. The slides were washed three times with PBS and sealed in VECTASHIELD Mounting Medium with DAPI (Vector Laboratories, Inc., Burlingame, CA, USA).

Comet assay. The comet assay was performed using the OxiSelect Comet assay kit (Cell Biolabs, Inc., San Diego, CA, USA) following the manufacturer's instructions (40). The cells were collected by trypsin digestion, washed twice with PBS, and then resuspended in $1.2 \%$ low-melting point agarose maintained at $37^{\circ} \mathrm{C}$. The density of the cells used was $1 \times 10^{5}$ cells $/ \mathrm{ml}$. A total of $80 \mu \mathrm{l}$ of cell-containing agarose was layered on a frosted glass slide. The slide was transferred to $4^{\circ} \mathrm{C}$ for $15 \mathrm{~min}$ and submerged in pre-cooled lysis buffer $(100 \mathrm{mM}$ EDTA, $2.5 \mathrm{M} \mathrm{NaCl}, 10 \mathrm{mM}$ Tris-HCl, $1 \%$ Triton $\mathrm{X}-100$ and $10 \%$ DMSO, $\mathrm{pH} 10.0$ ) at $4^{\circ} \mathrm{C}$ for $1.5 \mathrm{~h}$ in the dark. The slides were washed twice in enzyme buffer (40 mM HEPES, $0.1 \mathrm{M}$ $\mathrm{KCl}, 0.5 \mathrm{mM}$ EDTA and $0.2 \mathrm{mg} / \mathrm{ml} \mathrm{BSA}, \mathrm{pH} 8.0$ ) and then incubated in enzyme buffer with or without 8-oxoguanine glycosylase (OGG1; $1.0 \mu \mathrm{g} / \mathrm{ml}$; OriGene Technologies, Inc., Rockville, MD, USA) at $37^{\circ} \mathrm{C}$ for $45 \mathrm{~min}$. Following brief washing with enzyme buffer, the slides were denatured in pre-cooled alkaline buffer ( $300 \mathrm{mM} \mathrm{NaOH}, 1 \mathrm{mM}$ EDTA) in an electrophoresis chamber for $30 \mathrm{~min}$ and then electrophoresis was performed under $300 \mathrm{~mA}$ and $50 \mathrm{~V}$ for $30 \mathrm{~min}$. The slides were incubated in cooled neutralizing buffer $(250 \mathrm{mM}$ Tris- $\mathrm{HCl}, \mathrm{pH} 7.5$ ) for $30 \mathrm{~min}$, immersed in cold $70 \%$ ethanol for $5 \mathrm{~min}$ and then dried in air. The cells on the slides were stained with Vista Green DNA dye at room temperature for $15 \mathrm{~min}$ in the dark. The images were captured using an
Olympus fluorescent microscope (Olympus Corporation, Tokyo, Japan). The tail moment was defined as percentage of tail DNA $x$ tail length, quantified using the CASP software (Perceptive Instruments, Ltd., Edmunds, UK).

Western blot analysis. The cells were washed twice with PBS and removed from the plate using a scraper and $100 \mu \mathrm{l}$ radioimmunoprecipitation buffer $(150 \mathrm{mM} \mathrm{NaCl}, 1.0 \%$ IGEPAL CA-630, $0.5 \%$ sodium deoxycholate, $0.1 \%$ sodium dodecyl sulfate and $50 \mathrm{mM}$ Tris, $\mathrm{pH} 8.0$ ) containing $1 \mathrm{mM}$ phenylmethane sulfo-nylfluoride (Santa Cruz Technology, Inc., Dallas, TX, USA).

Following centrifugation at $12,000 \mathrm{x}$ g for $20 \mathrm{~min}$ at $4^{\circ} \mathrm{C}$, the protein concentration levels in the supernatants were measured using a bicinchoninic acid kit (Beijing Dingguo Changsheng Biotechnology Co., Ltd., Beijing, China). The samples were denatured at $95^{\circ} \mathrm{C}$ for $10 \mathrm{~min}$, separated on a $12 \%$ SDS-PAGE gel and transferred to a polyvinylidene difluoride membrane (EMD Millipore). The membranes were blocked in Tris-buffered saline with Tween-20 [10 mM Tris (pH 7.5), $100 \mathrm{mM} \mathrm{NaCl}, 0.1 \%$ Tween-20; PBST) containing $5 \%(\mathrm{w} / \mathrm{v})$ nonfat milk for $2 \mathrm{~h}$ at room temperature, followed by incubation with primary antibodies overnight at $4^{\circ} \mathrm{C}$ [B-cell lymphoma 2 (Bcl-2; 1:500; cat. no. sc-7382) and apoptosis regulator Bax (Bax; 1:500; cat. no. sc-7480) from Santa Cruz Biotechnology, Inc.; cleaved caspase 3 (1:500; cat. no. ab2302), cleaved caspase 9 (1:200; cat. no. ab2324) and X-linked inhibitor of apoptosis protein (XIAP; 1:1,000; cat.no.ab28151) from Abcam (Cambridge,UK); cyclin-dependent kinase 1 (CDK1)-pT14 (1:1,000; cat. no. bs-3091R), cell division cycle 25C (CDC25C)-pS216 (1:1,000; cat. no. bs-3096R), $\beta$-actin (1:5,000; cat. no. bs-0061R) and matrix metalloproteinase 9 (MMP9; 1:1,000; cat. no. bs-4593R) from BIOSS]. Subsequently, the membranes were incubated with a horseradish peroxidase-conjugated goat-anti-rabbit (1:10,000; cat. no. 111-035-003; Jackson ImmunoResearch Laboratories, Inc.) secondary antibody for $1 \mathrm{~h}$ at room temperature. The signals were visualized with an ECL kit (EasySee Western Blot kit; Beijing Transgen Biotech Co., Ltd., Beijing, China).

Cell cycle analysis. Following drug treatment, the cells were collected by trypsin digestion, washed twice with PBS, and fixed in $70 \%$ alcohol at $-20^{\circ} \mathrm{C}$ for $1 \mathrm{~h}$. Fixed cells were resuspended in $300 \mathrm{ml}$ of freshly prepared PBS with $0.1 \%$ Triton X-100, $0.2 \mathrm{mg} / \mathrm{ml}$ DNase-free RNase A (Sigma-Aldrich; Merck KGaA), $10 \mu \mathrm{g} / \mathrm{ml}$ propidium iodide (Roche Diagnostics, Basel, Switzerland), and incubated at $37^{\circ} \mathrm{C}$ for $20 \mathrm{~min}$ in the dark. The cells were filtered through a Filcon nylon mesh (BD Biosciences) and analyzed using a FACScalibur flow cytometer and ModFit software (BD Biosciences).

Apoptosis analysis by flow cytometry. Following drug treatment, cells were collected by trypsin digestion, washed twice with PBS and stained in working solution using an Annexin V-fluorescein isothiocyanate/PI dual staining kit (BestBio Science, Shanghai, China) according to the manufacturer's instructions. The stained cells were analyzed by the FACScalibur flow cytometer and the CellQuest software (BD Biosciences). 
Mitochondrial membrane potential measurement. The mitochondrial membrane potential was measured using the JC-1 dye (Beyotime Institute of Biotechnology) according to the manufacturer's instructions. The cells were washed twice with PBS, incubated with $1 \mathrm{ml} \mathrm{JC}-1$ working solution for $20 \mathrm{~min}$ at $37^{\circ} \mathrm{C}$, and sealed in VECTASHIELD medium (Vector Laboratories). Cell images were imaged with an Olympus fluorescent microscope.

Statistical analysis. The data are expressed as the mean \pm standard deviation and the results were representative of three independent experiments. All statistical analyses were performed using the GraphPad Prism software (GraphPad Software, Inc., La Jolla, CA, USA). The statistical comparisons between two groups were performed by unpaired two-tailed Student's t-test and multigroup comparisons were conducted by using two-way ANOVA followed by the Dunnett or Tukey test. $\mathrm{P}<0.05$ was considered to indicate a statistically significant difference.

\section{Results}

Cytotoxicity of icaritin against HeLa and SiHa cervical cancer cells. It has been reported that icaritin (Fig. 1A) induces considerable cytotoxicity against several different types of cancer cells by mechanisms that are not yet fully understood (26-34). To examine the effects of icaritin on cervical cancer, the cytotoxicity of icaritin against human HeLa and $\mathrm{SiHa}$ cells was analyzed. HeLa and SiHa cancer cells were treated with a concentration range of icaritin for 24,48 and/or $72 \mathrm{~h}$. The results of the MTT assay indicated that the proliferation rates of $\mathrm{HeLa}$ and $\mathrm{SiHa}$ cancer cells were significantly suppressed by icaritin (Fig. 1B-D). Following $48 \mathrm{~h}$ of treatment, the half maximal inhibitory concentration $\left(\mathrm{IC}_{50}\right)$ values of icaritin for HeLa and SiHa cells were 12.5 and $17 \mu \mathrm{M}$, respectively (Fig. 1B). The viabilities of HeLa and SiHa cells were reduced to 47.5 and $60 \%$, respectively, following treatment by $12.5 \mu \mathrm{M}$ icaritin for $48 \mathrm{~h}$, while those of the non-cancerous CCD-1095Sk fibroblasts and H293 epithelial cells were not changed (Fig. 1C). These results indicated that icaritin was selectively more toxic to cancer cells. Overall, the inhibition of cancer cell proliferation by icaritin exhibited optimal doseand time-dependency (Fig. 1D).

Subsequently, a colony formation assay was used to confirm the inhibitory activity of icaritin against HeLa and SiHa cervical cancer cells. After 8 days of treatment with icaritin at the $\mathrm{IC}_{50}$ determined in the cytotoxicity assay, fewer and smaller colonies were observed for SiHa and HeLa cells compared with $0 \mu \mathrm{M}$ treatment (Fig. $2 \mathrm{~A}$ and B). In contrast to this dose treatment, higher concentration levels of icaritin (equivalent to $2 \mathrm{x} \mathrm{IC}_{50}$ ) resulted in further inhibition of cellular proliferation (Fig. 2A and B). However, the growth curves of the non-cancerous CCD-1095Sk fibroblasts and 293 epithelial cells that were treated with the same concentration points were much less affected (data not shown). Taken collectively, these results suggested that icaritin dose-dependently and selectively suppressed the growth of HeLa and SiHa cervical cancer cells.

In addition to these proliferation and survival assays, the impact of icaritin on the growth and/or migration of HeLa and SiHa cervical cancer cells was further analyzed in wound healing assays. The growth and/or migration of both HeLa and SiHa cells were significantly decreased in the presence of icaritin (Fig. 2C and D). Given the effects revealed by the MTT and colony formation assays above, the decreased wound healing was likely a result of an inhibitory effect on proliferation, rather than on migration.

Icaritin increases ROS levels in cervical cancer cells. Icaritin has been reported to stimulate ROS generation in specific cell types (34-38). To determine whether icaritin could induce ROS generation in HeLa and SiHa cervical cancer cells, the fluorescent probe DCFH-DA was used to measure total cellular ROS. Treatment with icaritin at concentrations equivalent to the $\mathrm{IC}_{50}$ values for $12 \mathrm{~h}$ caused a significant increase in ROS levels in HeLa and SiHa cancer cells, which was blocked by pre-treatment with $5 \mathrm{mM} \mathrm{NAC} \mathrm{(Fig.} \mathrm{3A} \mathrm{and} \mathrm{B).} \mathrm{A} \mathrm{significant}$ increase in ROS levels was noted as early as $3 \mathrm{~h}$ after initiation of icaritin treatment (Fig. 3C), whereas a longer treatment did not result in an additional increase in ROS levels. Notably, the inhibition of icaritin-induced ROS increase by NAC significantly reduced the cytotoxicity of icaritin against HeLa and SiHa cells (Fig. 3D). These results suggested that treatment of cervical cancer cells with icaritin caused a rapid and robust increase in ROS levels, which contributed to the suppression of cancer cell proliferation by icaritin.

Icaritin-induced ROS overload results in extensive DNA breaks. Elevated ROS levels results in oxidative stress, which can damage cellular components and affect cell survival. For example, repair of ROS-oxidized deoxynucleotides in DNA, such as 8-oxo-2'-deoxyguanosine (8-oxo-dG), may result in accumulation of repair-associated DNA strand breaks, and subsequent induction of cell cycle arrest and programmed cell death (41). To gain insight into the physiological implications of the icaritin-induced ROS overload in cancer cells, the number of DNA strand breaks prior to and following treatment with icaritin was compared using the comet assay (single-cell gel electrophoresis). Alkaline conditions were used to convert all single-strand DNA breaks (SSB) to double-strand breaks (DSB), suggesting that the size and intensity of the comet tail (tail moment) was proportional to the number of total DNA strand breaks (SSBs + DSBs). The results indicated that after $24 \mathrm{~h}$ incubation of HeLa and $\mathrm{SiHa}$ cancer cells with $1 \mathrm{x} \mathrm{IC}_{50}$ icaritin $(12.5 \mu \mathrm{M}$ for HeLa, $17 \mu \mathrm{M}$ for $\mathrm{SiHa})$, the number of cancer cells with a comet tail, and the size and intensity of the comet tail (tail moment), were increased (Fig. 4A and B). Treatment with $2 \mathrm{x} \mathrm{IC}_{50}$ of icaritin $(25 \mu \mathrm{M}$ for HeLa, $34 \mu \mathrm{M}$ for $\mathrm{SiHa}$ ) further increased the number of comet tail-containing cells and their corresponding tail size (Fig. 4A). These effects were blocked by pre-treatment with the ROS inhibitor NAC, indicating that the DNA strand breaks occurred via ROS production (Fig. 4C).

OGG1 is a glycosylase that specifically removes the oxidized guanine base of 8 -oxo-dG in DNA, leaving an apurinic site, which can be converted into a DSB during an alkaline comet assay. Thus, incubation of the cells with OGG1 prior to electrophoresis can aid the assessment of the amount of 8-oxo-dG in DNA during the comet assay. The data indicated that incubation of icaritin-treated cells with OGG1 further increased the tail moments (Fig. 4B), suggesting that 

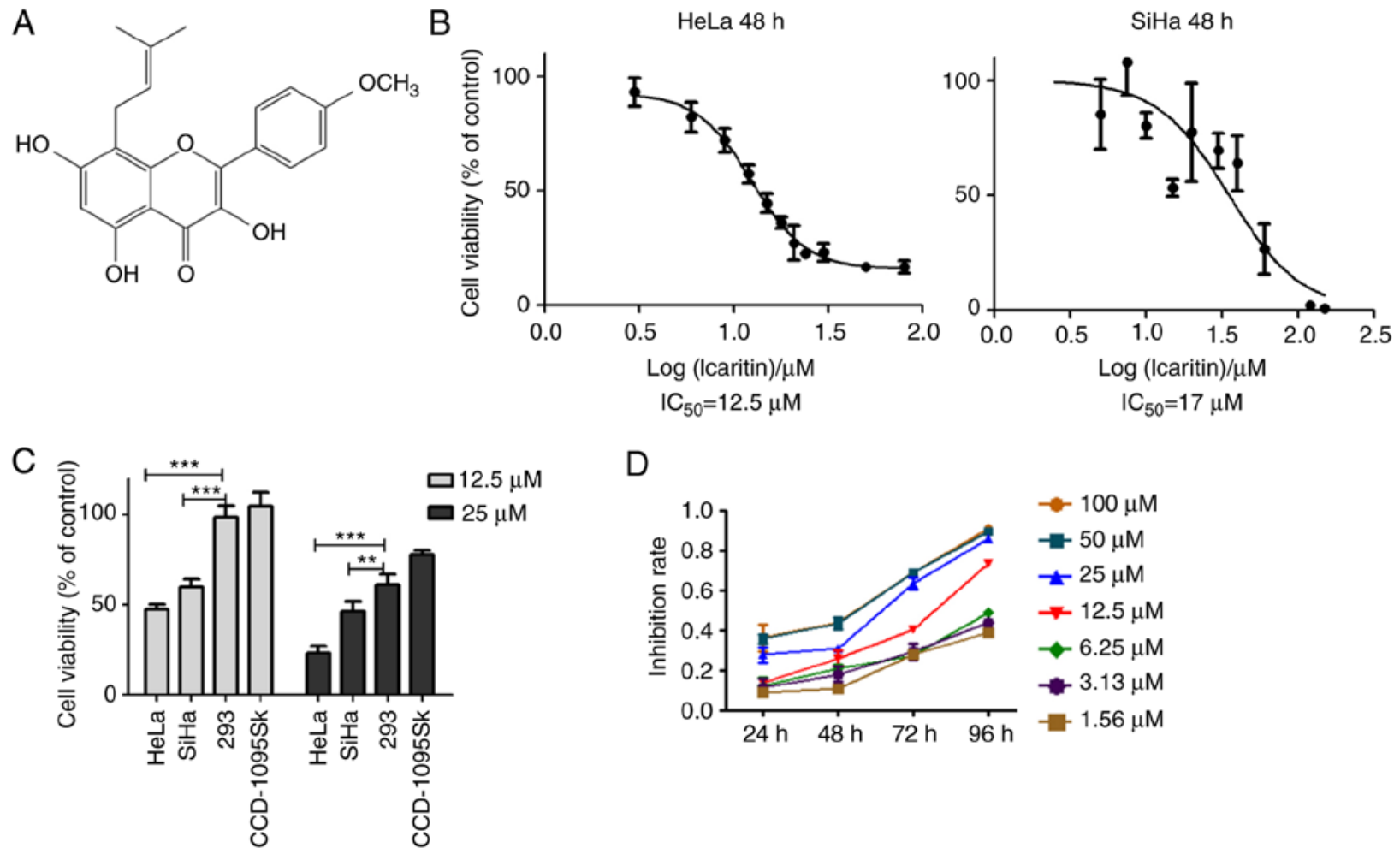

Figure 1. Cytotoxicity of icaritin against cervical cancer cells. (A) Chemical structure of icaritin. (B) HeLa and SiHa cervical cancer cells treated with 0,3 , $6,9,12,15,18,21,24,30,50$ or $80 \mu \mathrm{M}$ of icaritin for $48 \mathrm{~h}$ and cell viability determined by MTT assay. The results were analyzed using the GraphPad Prism software by nonlinear regression (curve fit). (C) Sensitivity of different types of cells: HeLa and SiHa cancer cells, and CCD-1095Sk and 293 non-cancerous cells, were treated with $12.5 \mu \mathrm{M}$ or $25 \mu \mathrm{M}$ of icaritin for $48 \mathrm{~h}$ and cell viability was determined by the MTT assay $\left(\mathrm{n}=3\right.$, mean \pm standard deviation; ${ }^{* *} \mathrm{P}<0.01$; $\left.{ }^{* * * *} \mathrm{P}<0.001\right)$. (D) Time- and dose-dependency; representative results of HeLa cells. $\mathrm{IC}_{50}$, half maximal inhibitory concentration.

icaritin-induced ROS overload caused extensive oxidative DNA damage, which subsequently resulted in large numbers of DNA breaks.

Subsequently, immunostaining was used to directly visualize and quantify cellular DSBs by analyzing the DSB markers $\gamma \mathrm{H} 2 \mathrm{AX}$ and 53BP1. Treatment with icaritin for $12 \mathrm{~h}$ caused a dramatic increase in the number of cells with brightly stained nuclear 53BP1 and $\gamma \mathrm{H} 2 \mathrm{AX}$ foci (Fig. 5A-C). The earliest increase in the foci of $\gamma \mathrm{H} 2 \mathrm{AX}$ was noted at $3 \mathrm{~h}$ post-icaritin treatment, and for 53BP1 it was noted at $6 \mathrm{~h}$ post-icaritin treatment in HeLa (Fig. 5B) and $\mathrm{SiHa}$ cancer cells (Fig. 5C). Higher concentration of icaritin resulted in a higher number of positive cells and higher number of positive foci per cell. Pre-incubation with $5 \mathrm{mM}$ NAC completely blocked the icaritin-induced increase in 53BP1 and $\gamma \mathrm{H} 2 \mathrm{AX}$ staining (data not shown).

Icaritin treatment arrests cervical cancer cell growth at the $G_{2} / M$ phases. To assess the consequences of the icaritin-induced DNA damage, icaritin-induced changes in the cell cycle distribution were analyzed by flow cytometry. The results revealed that icaritin increased the percentage of cells at the $\mathrm{G}_{2} / \mathrm{M}$ phase, while slightly decreasing the percentage of cells at the $\mathrm{S}$ phase (Fig. 6). Following treatment with $25 \mu \mathrm{M}$ icaritin for $24 \mathrm{~h}$, the percentage of HeLa cells at the $\mathrm{G}_{2} / \mathrm{M}$ phase was increased from 6.23 to $19.43 \%$. A similar effect was noted after treatment SiHa treatment with $34 \mu \mathrm{M}$ icaritin for $24 \mathrm{~h}$ (Fig. 6A). The percentage of SiHa cells at the $\mathrm{G}_{2} / \mathrm{M}$ phases was increased from 4.15 to $17.35 \%$ (Fig. 6A). When the cells were pre-incubated with NAC, the increase in the percentage of $\mathrm{G}_{2} / \mathrm{M}$ cells was partially rescued (Fig. $6 \mathrm{~A}$ and $\mathrm{B}$ ). These results indicated that icaritin-induced ROS caused cell cycle arrest and blocked the progression of cervical cancer cells to the $\mathrm{G}_{2} / \mathrm{M}$ phases of the cell cycle.

Icaritin induces apoptosis in HeLa and SiHa cervical cancer cells. Consistent with the observations of cell cycle analysis, examination of the nuclear morphology of icaritin-treated HeLa cells demonstrated that icaritin dose-dependently increased the number of apoptosis hallmarks, namely pyknosis and condensed chromatin (Fig. 7A). This suggested that apoptosis was induced by icaritin treatment.

The percentage of apoptotic cells was analyzed by Annexin V and propidium (PI) double-staining and flow cytometry. The data demonstrated that icaritin dose- and time-dependently induced apoptosis in $\mathrm{HeLa}$ and $\mathrm{SiHa}$ cells (Fig. 7B and C). Following treatment with icaritin ( $1 \mathrm{x} \mathrm{IC}_{50}$ and $2 \mathrm{x} \mathrm{IC}_{50}$ ) for $24 \mathrm{~h}$, the percentage of apoptotic HeLa cells increased to 8.67 and $12.35 \%$, respectively, and the percentage of apoptotic SiHa cells increased to 15.61 and $23.16 \%$, respectively (Fig. 7B). Longer treatment $(48 \mathrm{~h})$ resulted in higher percentage of apoptotic cells (11.11 and $17.36 \%$ for HeLa, 30.05 and $33.11 \%$ for SiHa; Fig. 7B and C). Pre-incubation with NAC significantly blocked icaritin-induced apoptosis (Fig. 7C).

The loss of mitochondrial membrane potential is characteristic of the activation of the intrinsic apoptotic pathway. The mitochondria membrane potential probe, JC-1, was 
A

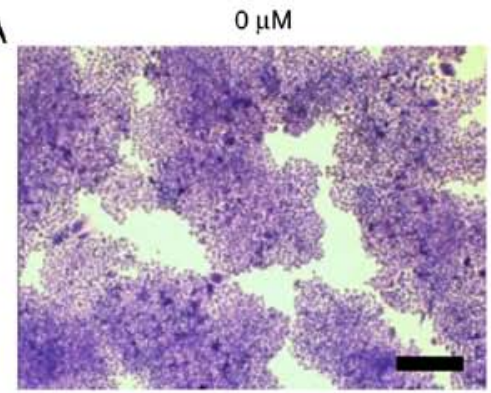

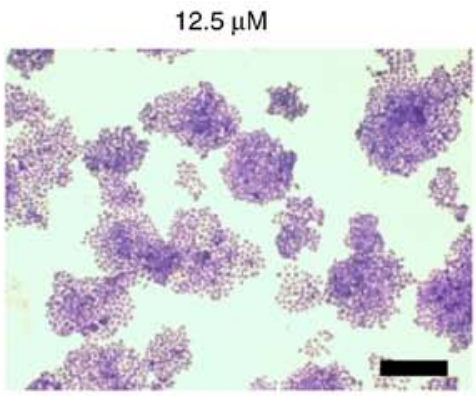

$25 \mu \mathrm{M}$

B
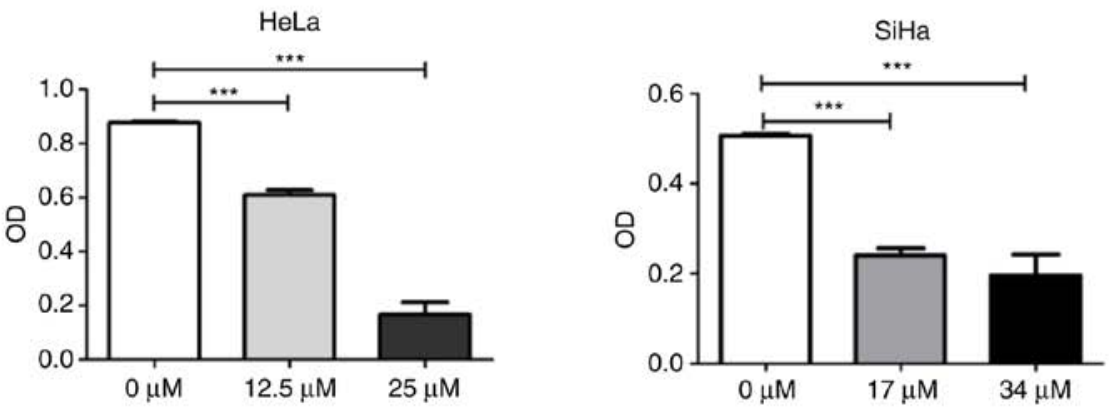

C
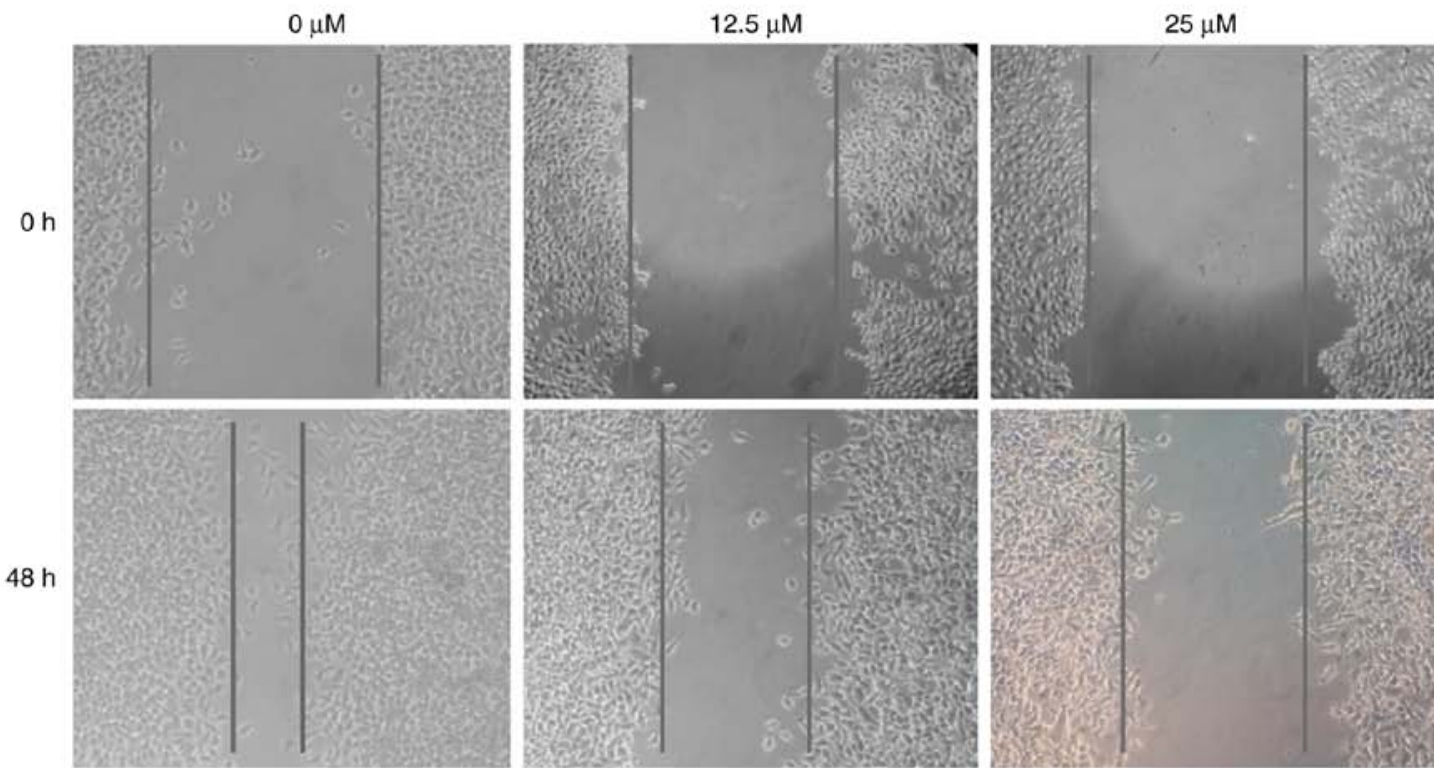

D
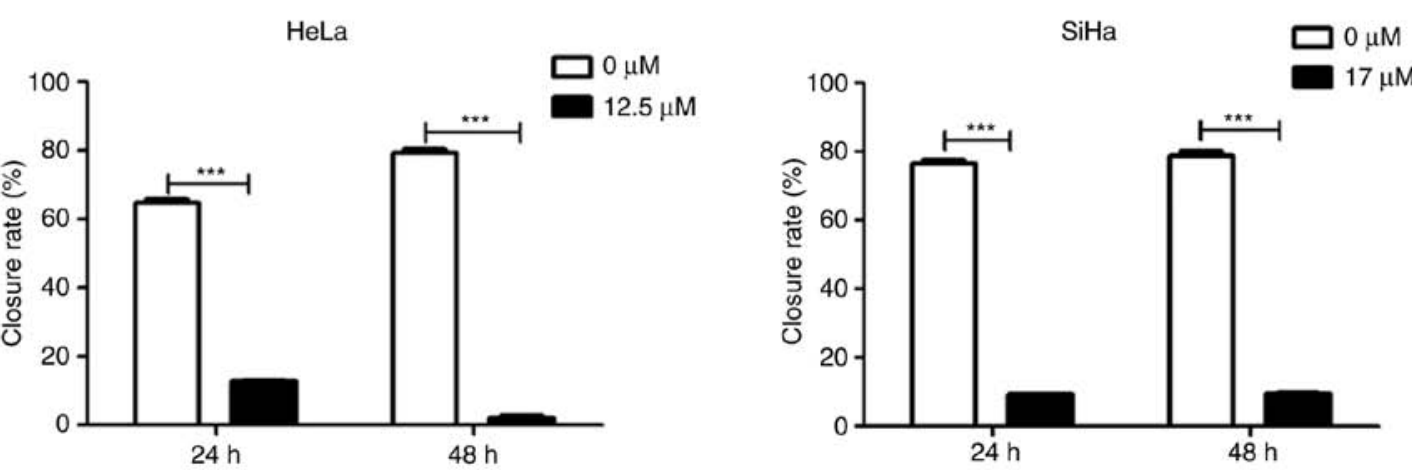

Figure 2. Colony formation and wound healing assay. (A) Colony formation assay. HeLa or SiHa cells were treated with icaritin for 8 days and stained with crystal violet (representative images of HeLa cells; scale bar, $200 \mu \mathrm{m}$ ). (B) Quantification of colony formation assay. Crystal violet-stained cells were dissolved in $70 \%$ alcohol, and absorbance at $595 \mathrm{~nm}$ (O.D.) was measured using a microplate reader and presented as mean \pm standard error from three independent experiments ( $\left.{ }^{* * *} \mathrm{P}<0.001\right)$. (C) Wound healing assay. Representative images of HeLa cells. (D) Quantification of wound healing assay. Closure rate was defined as follows: (original wound size-new wound size)/original wound size $\mathrm{x} 100\left(\mathrm{n}=3\right.$, mean \pm standard error; $\left.{ }^{* * *} \mathrm{P}<0.001\right)$. O.D., optical density.

used to assess the integrity of mitochondrial membranes in HeLa and SiHa cells. The results demonstrated that $24 \mathrm{~h}$ treatment with icaritin dose-dependently increased the intensity of green fluorescence, while the intensity of the 

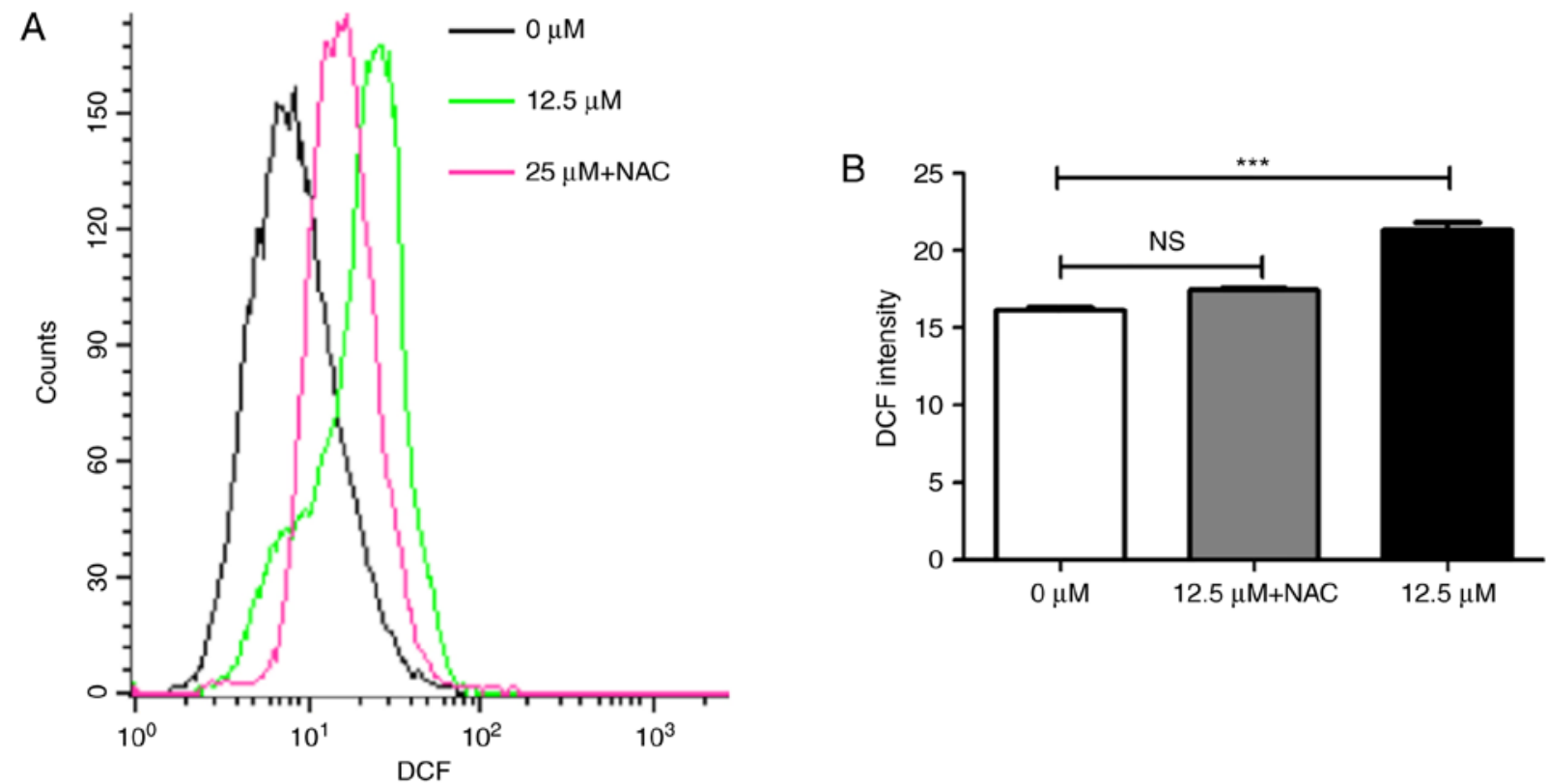

C
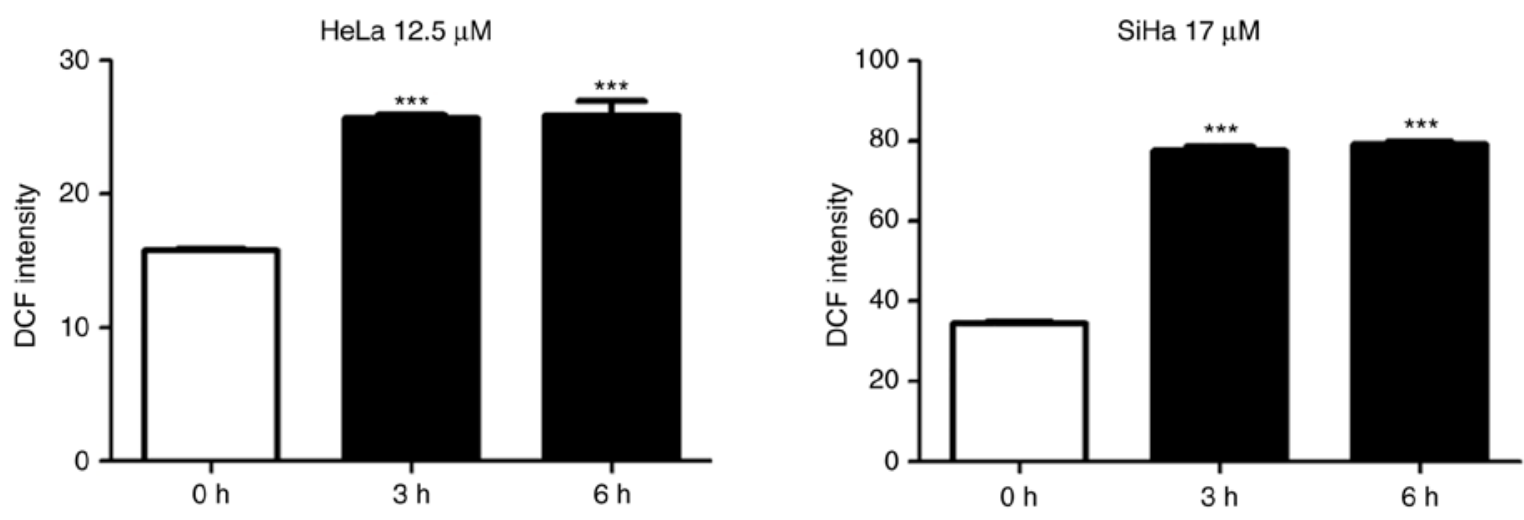

$\mathrm{D}$

HeLa $48 \mathrm{~h}$

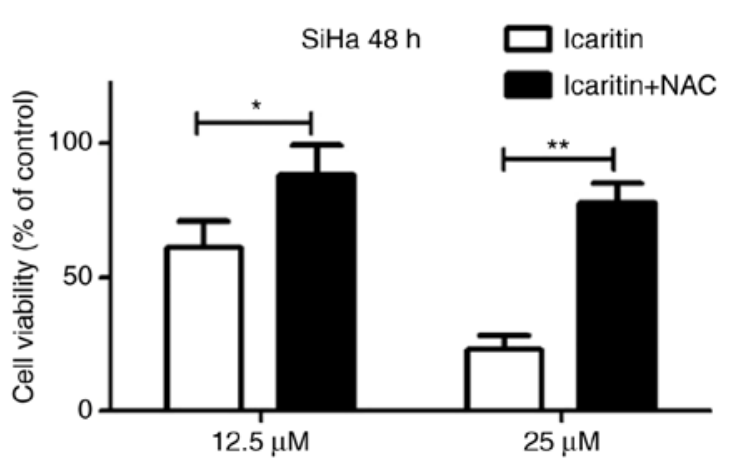

Figure 3. Measurement of total cellular ROS. (A) Flow cytometry analysis: HeLa or SiHa cells with or without $1 \mathrm{~h}$ pre-incubation with 5 mM NAC were treated by icaritin for $12 \mathrm{~h}$ and a representative result of HeLa cells was shown. (B) Data from three independent experiments in HeLa cells were processed by the GraphPad Prism software $\left({ }^{* * *} \mathrm{P}<0.001\right)$. (C) Time-dependent ROS accumulation. HeLa or SiHa cells were treated by icaritin for $3 \mathrm{~h}$ or longer $\left({ }^{* * *} \mathrm{P}<0.001\right)$. (D) Inhibition of icaritin cytotoxicity by NAC. HeLa or SiHa cells with or without pre-incubation $(1 \mathrm{~h})$ with $5 \mathrm{mM} \mathrm{NAC}$ were treated by icaritin for $48 \mathrm{~h}$ and cell survival was analyzed by the MTT assay $\left({ }^{*} \mathrm{P}<0.05 ;{ }^{* *} \mathrm{P}<0.01 ;{ }^{* * *} \mathrm{P}<0.001\right)$. ROS, reactive oxygen species; NAC, N-acetyl cysteine; DCF, dichlorofluorescin; NS, not significant.

red fluorescence decreased (Fig. 7D), suggesting a prompt dissipation of mitochondrial membrane potential and an activation of the intrinsic apoptotic pathway caused by icaritin treatment.

To further explore the mechanism of action of icaritin, western blot analysis was used to analyze the changes of proteins associated with apoptosis. Treatment of the cells with the icaritin $\mathrm{IC}_{50}$ for $24 \mathrm{~h}$ decreased MMP-9 levels in HeLa and SiHa cells, whereas NAC blocked the icaritin-induced decrease in MMP-9 (Fig. 8A). This indicated that ROS have a role in the downregulation of MMP-9, which may be involved in inhibited cell migration. The ATR serine/threonine kinase (ATR)-checkpoint kinase 1 (Chk1) axis senses DSBs and replication stress to regulate DNA repair, replication and cell cycle progression and/or induce apoptosis (42). Treatment of the cells with icaritin for $24 \mathrm{~h}$ resulted in reduced expression 
A

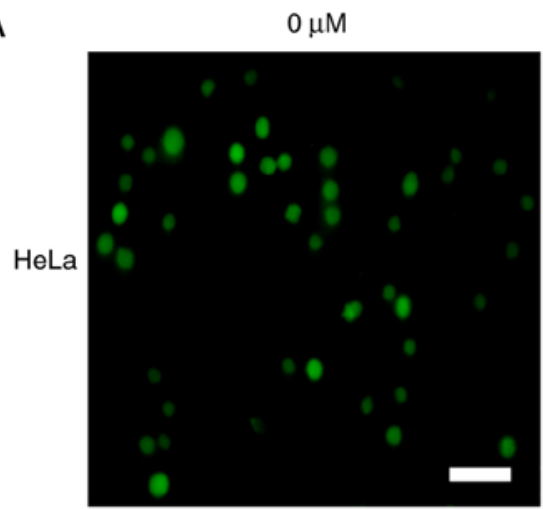

$0 \mu \mathrm{M}$

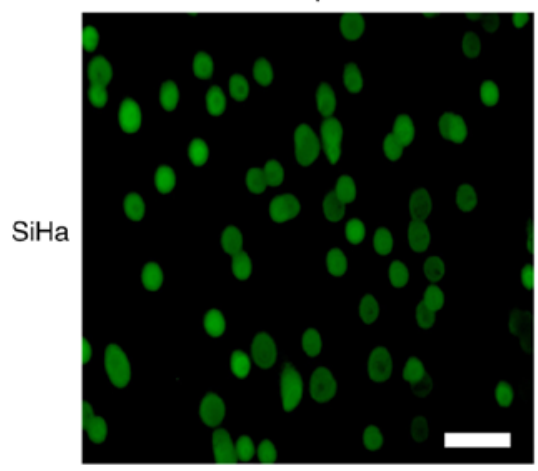

B

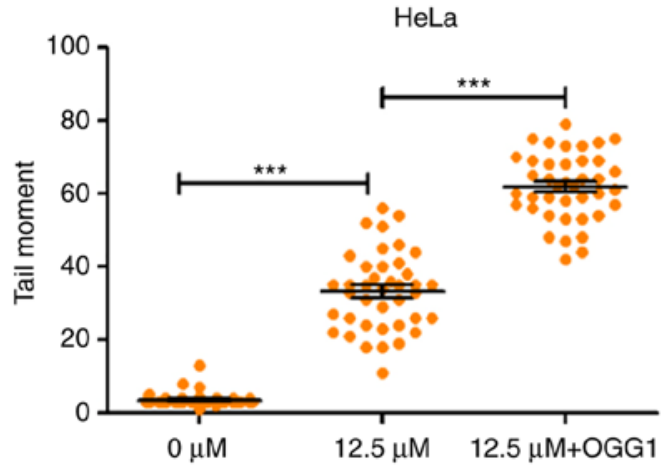

C

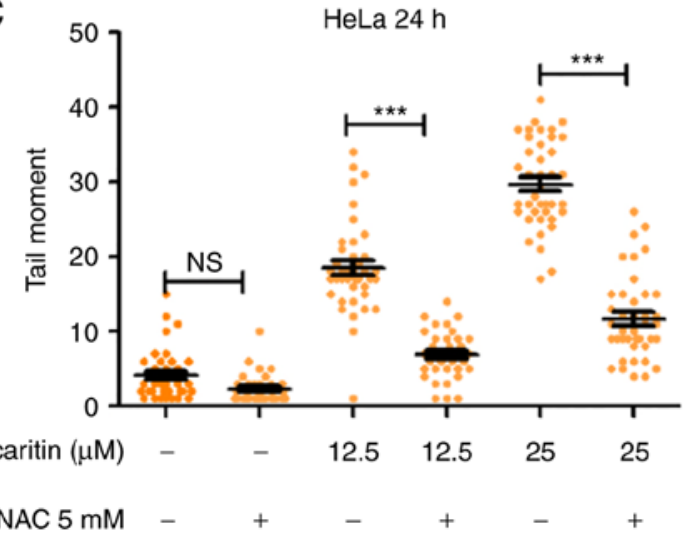

12.5

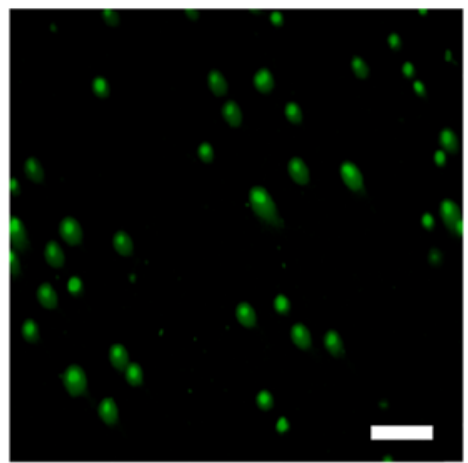

$17 \mu \mathrm{M}$

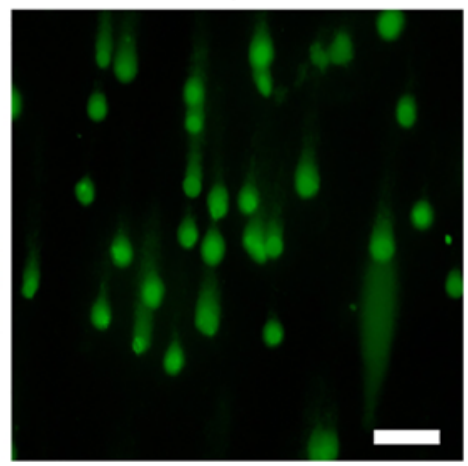

0

0
25

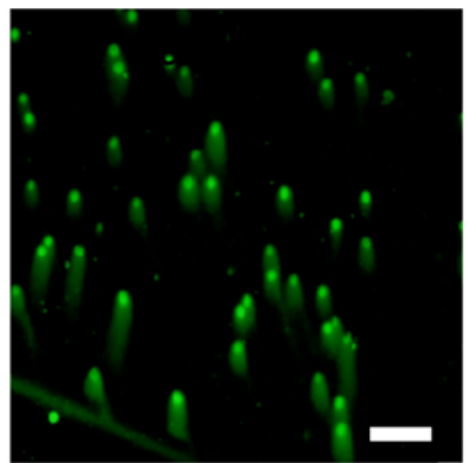

34

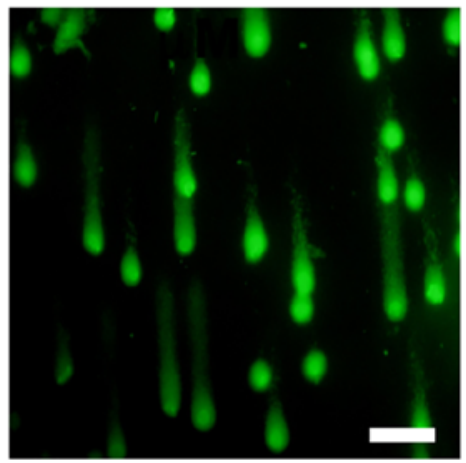

$\mathrm{SiHa}$

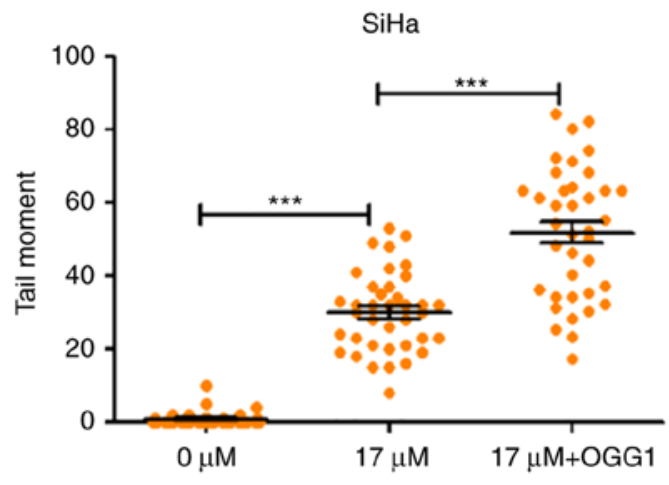

$\mathrm{SiHa} 24 \mathrm{~h}$

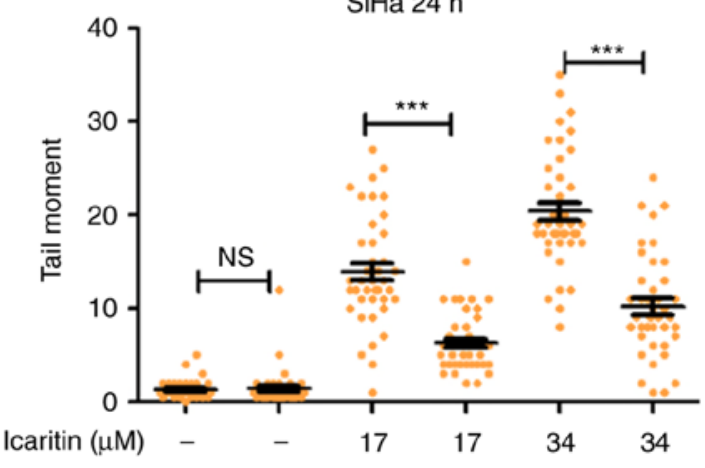

Figure 4. Comet assay. (A) HeLa and SiHa cells were treated by $1 \mathrm{x} \mathrm{IC}_{50}$ or $2 \mathrm{x} \mathrm{IC}_{50}$ icaritin and/or vehicle control for $24 \mathrm{~h}$ and a comet assay was used to identify DNA strand breaks (scale bar, $200 \mu \mathrm{m}$ ). (B) Quantification of tail moment. Tail moment was defined as percentage of tail DNA x tail length and was quantified using the CASP software $\left(\mathrm{n}=40 ;{ }^{* * *} \mathrm{P}<0.001\right)$. (C) Inhibition of DNA strand breaks by NAC. HeLa and SiHa cells with or without pre-incubation $(1 \mathrm{~h})$ with $5 \mathrm{mM}$ NAC were treated by icaritin for $24 \mathrm{~h}\left({ }^{* * *} \mathrm{P}<0.001\right) . \mathrm{IC}_{50}$, half maximal inhibitory concentration; OGG, 8-oxoguanine glycosylase; NAC, N-acetyl cysteine; NS, not significant.

levels of CDK1-pT14 and an increase in the expression levels of CDC25C-pS216 (Fig. 8B). Both changes were eliminated by NAC pre-treatment, indicating that ROS-associated activation of the ATR-Chk1 pathway occurs in icaritin-treated 
A

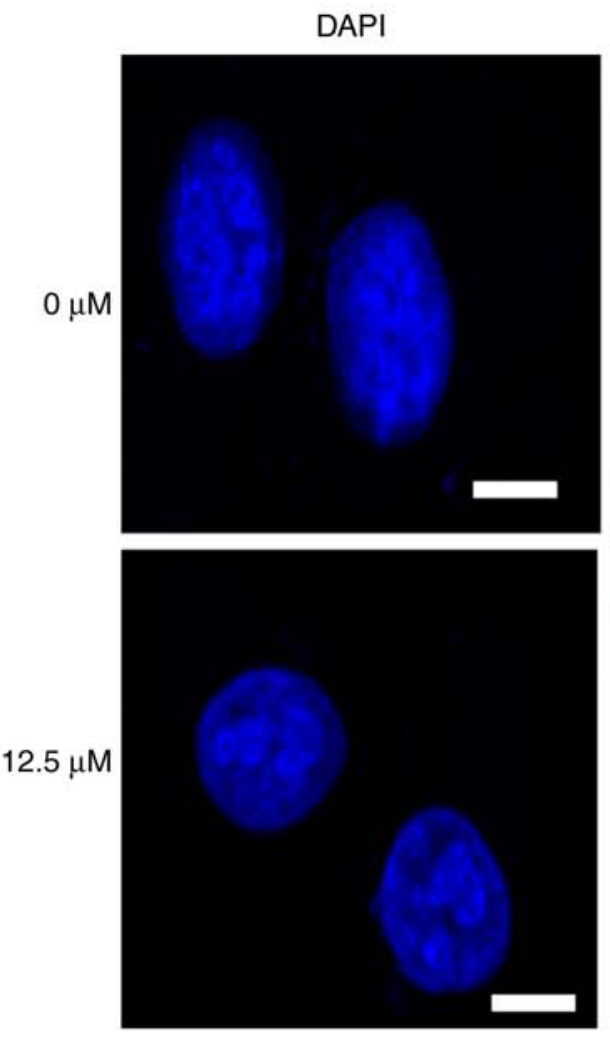

DAPI
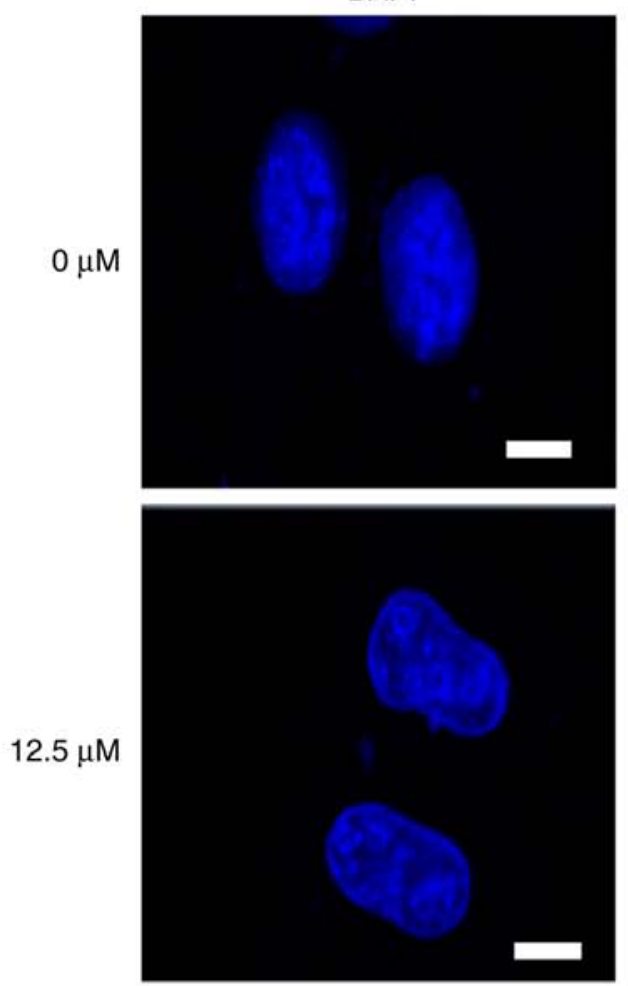

53BP1
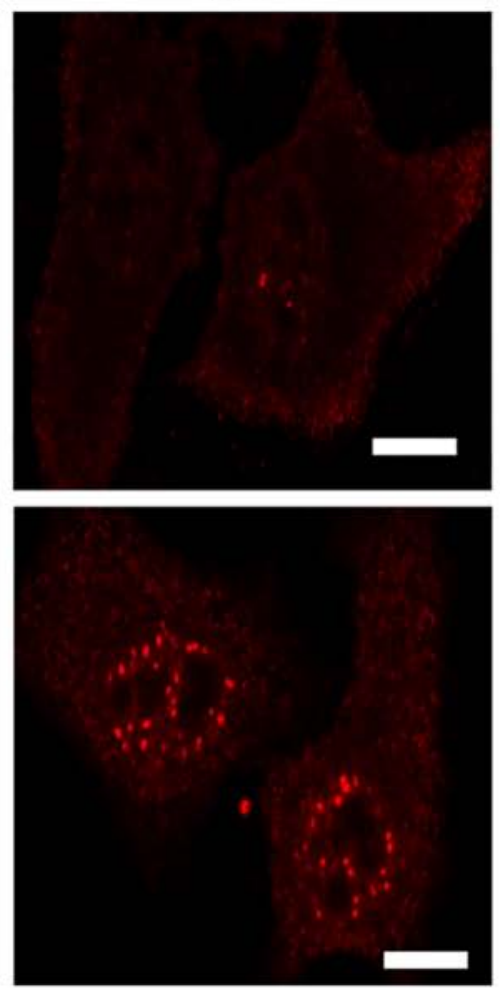

$\gamma H 2 A X$
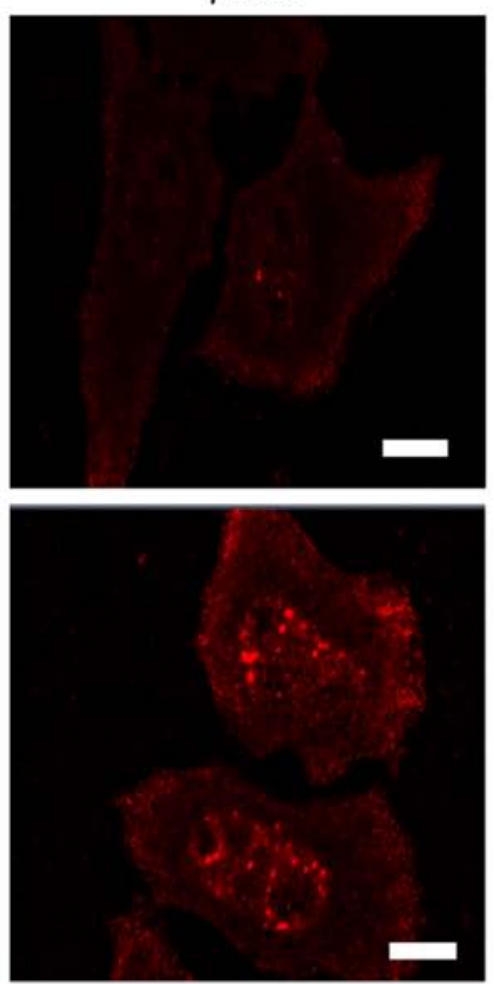

Merged

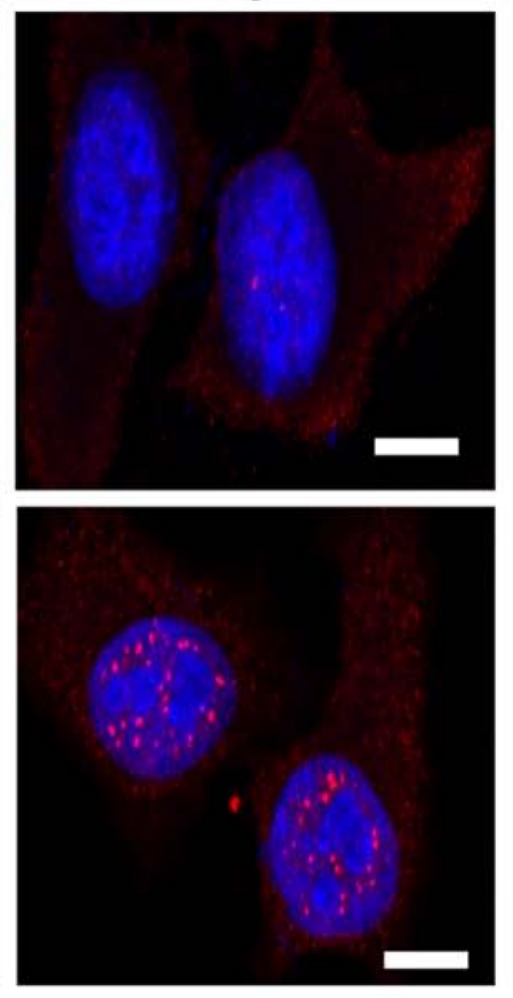

Merged
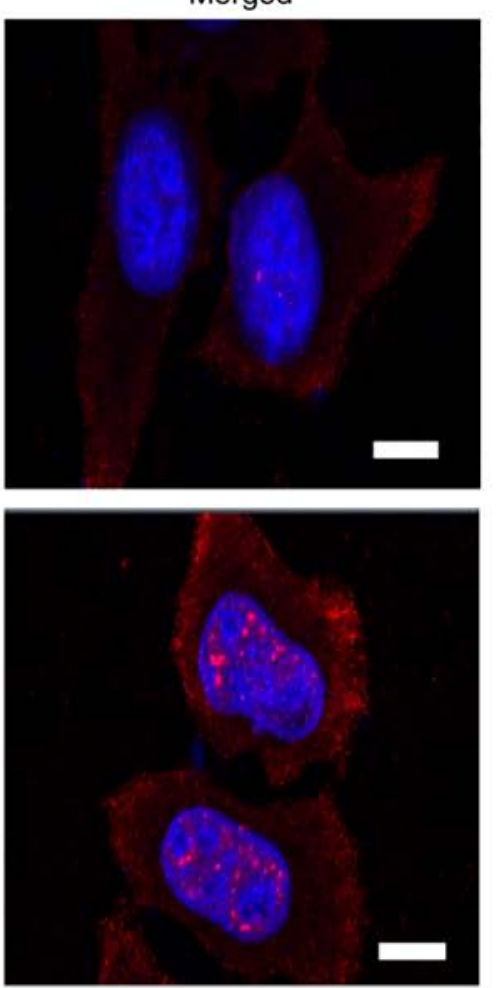

Figure 5. Immunostaining of $\gamma \mathrm{H} 2 \mathrm{AX}$ and 53BP1. (A) HeLa cells were treated with $12.5 \mu \mathrm{M}$ icaritin and/or vehicle control for $12 \mathrm{~h}$ (scale bar, $10 \mu \mathrm{m}$ ).

cancer cells, and that inhibition of CDK1 activity was potentially responsible for arresting the cell cycle at the $\mathrm{G}_{2} / \mathrm{M}$ phase. Finally, treatment of the cells with icaritin for $24 \mathrm{~h}$ dose-dependently increased the levels of the pro-apoptotic protein Bax, and the levels of activated caspase 3 and 9 enzymes; whereas, it concomitantly decreased the levels of the anti-apoptotic proteins, Bcl-2 and XIAP (Fig. 8C and D). These findings suggest that icaritin activated the intrinsic apoptotic pathway, potentially as a result of the DDR signaling pathway. 
B
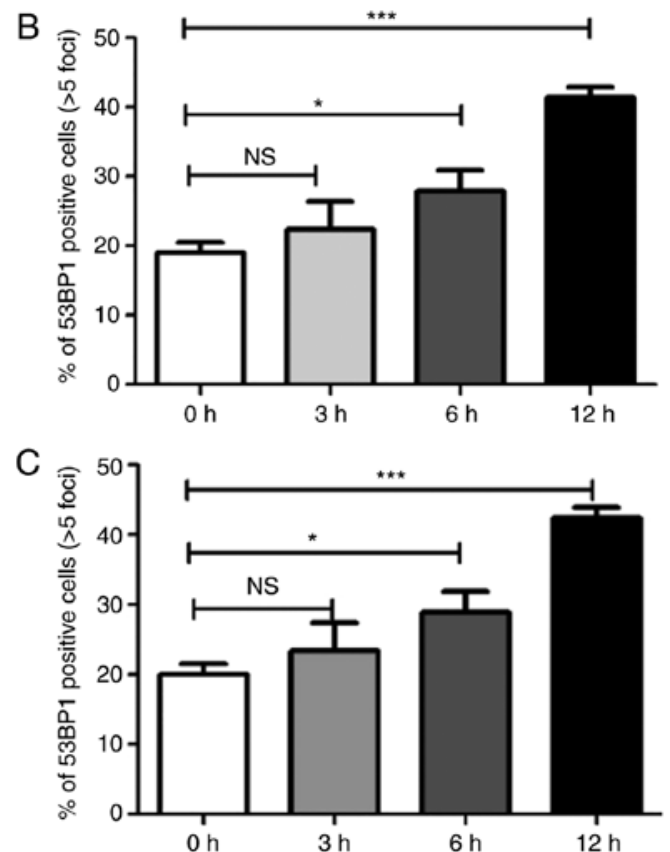
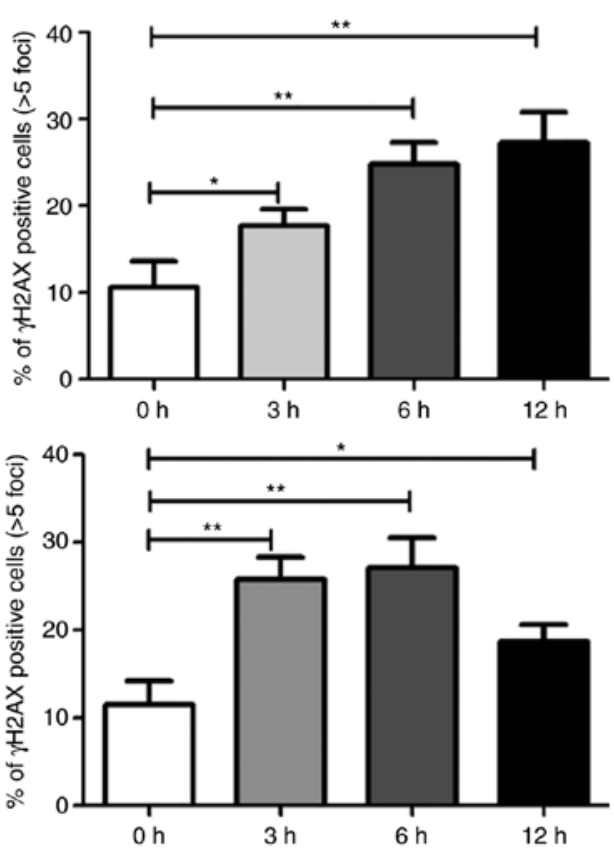

Figure 5. Continued. Time course of $\gamma \mathrm{H} 2 \mathrm{AX}$ and 53BP1 induction in (B) HeLa and (C) SiHa cells; the number of cells with five or more bright 53BP1 or $\gamma \mathrm{H} 2 \mathrm{AX}$ foci in three cover slips was counted manually $\left({ }^{*} \mathrm{P}<0.05 ;{ }^{* *} \mathrm{P}<0.01 ;{ }^{* * * *} \mathrm{P}<0.001\right)$. 53BP1, TP53-binding protein $1 ; \gamma \mathrm{H} 2 \mathrm{AX}, \gamma \mathrm{H} 2 \mathrm{AX}$ histone; NS, not significant.

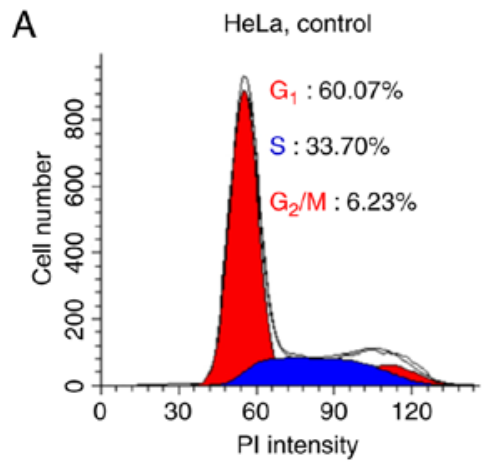

$\mathrm{SiHa}$, control

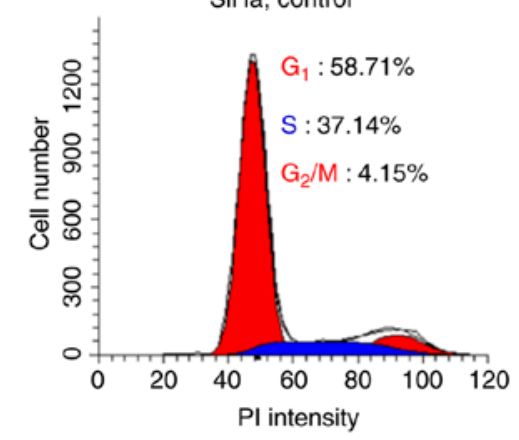

B

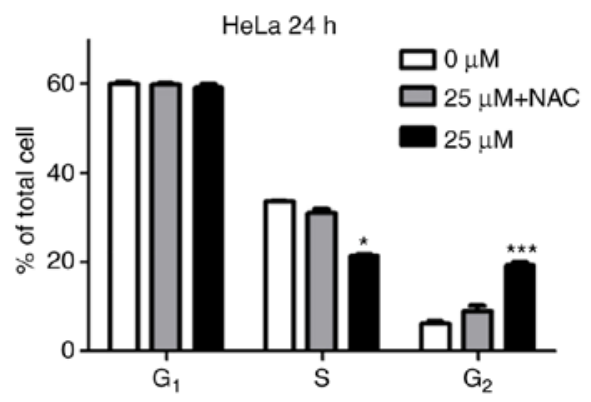

HeLa, $25 \mu \mathrm{M}$
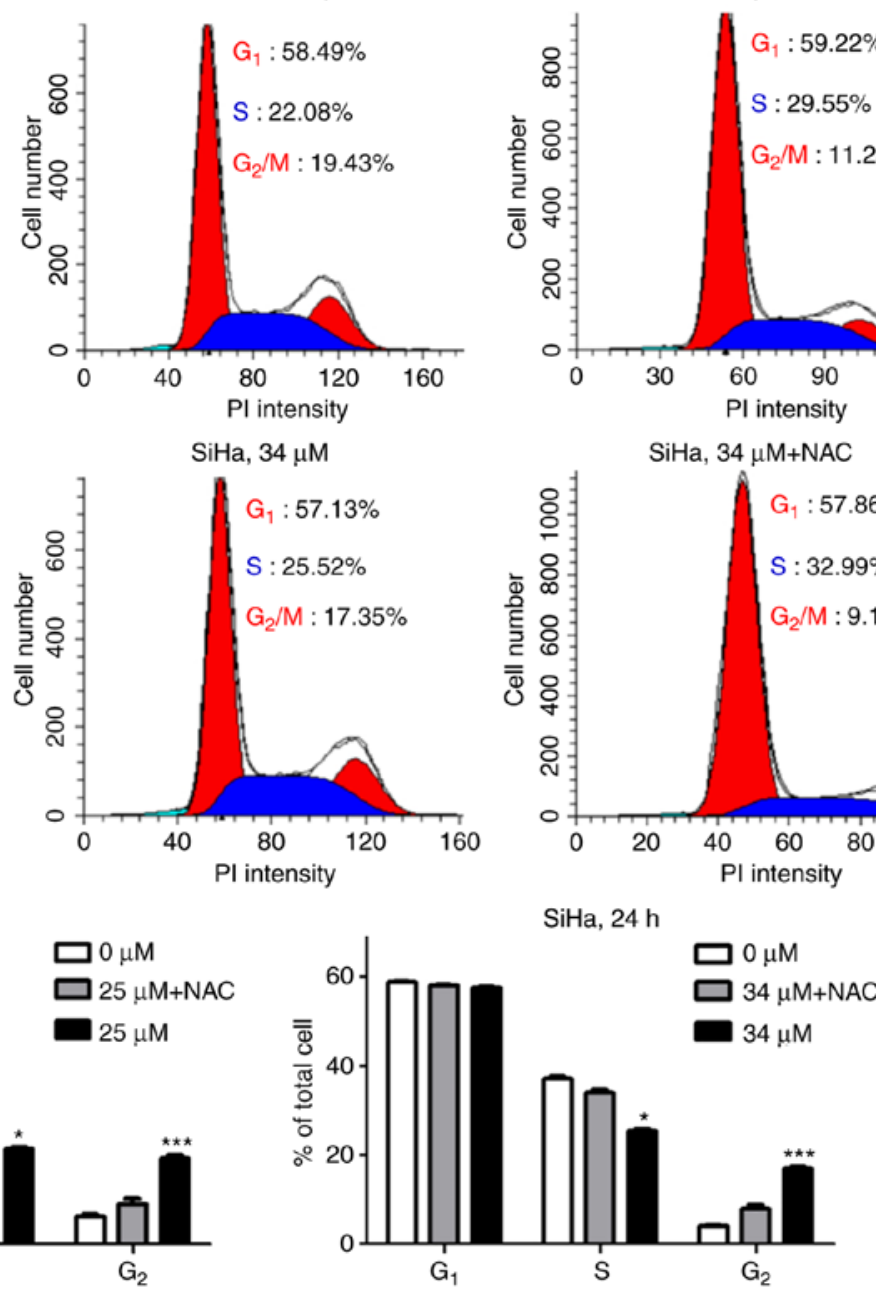

Figure 6. Cell cycle analysis. (A) Cell cycle analysis was performed by flow cytometry. HeLa or SiHa cells with or without pre-incubation (1 h) with $5 \mathrm{mM}$ NAC were treated by $25 \mu \mathrm{M}$ or $34 \mu \mathrm{M}$ of icaritin for $24 \mathrm{~h}$. (B) Quantification of flow cytometry data from three independent experiments ("P<0.05 vs. $0 \mu \mathrm{M}$ group; ${ }^{* * * *} \mathrm{P}<0.001$ vs. $0 \mu \mathrm{M}$ group). NAC, $\mathrm{N}$-acetyl cysteine. 
A
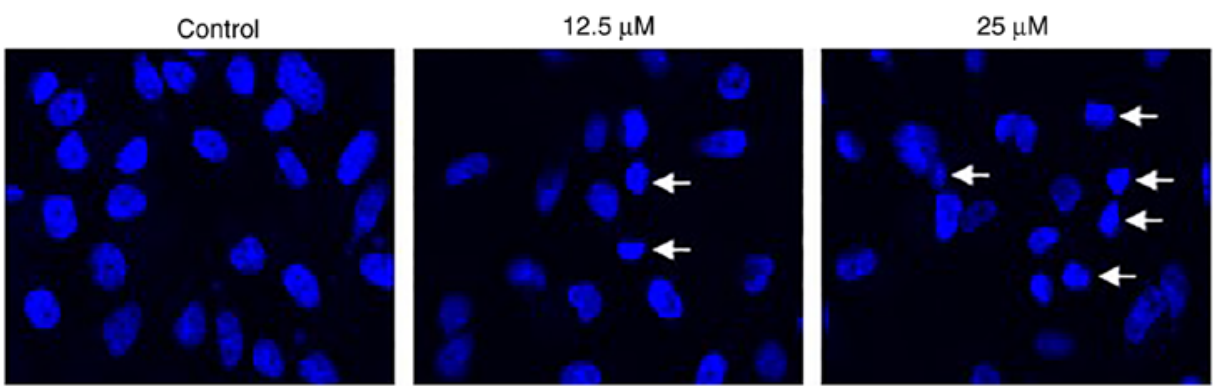

B
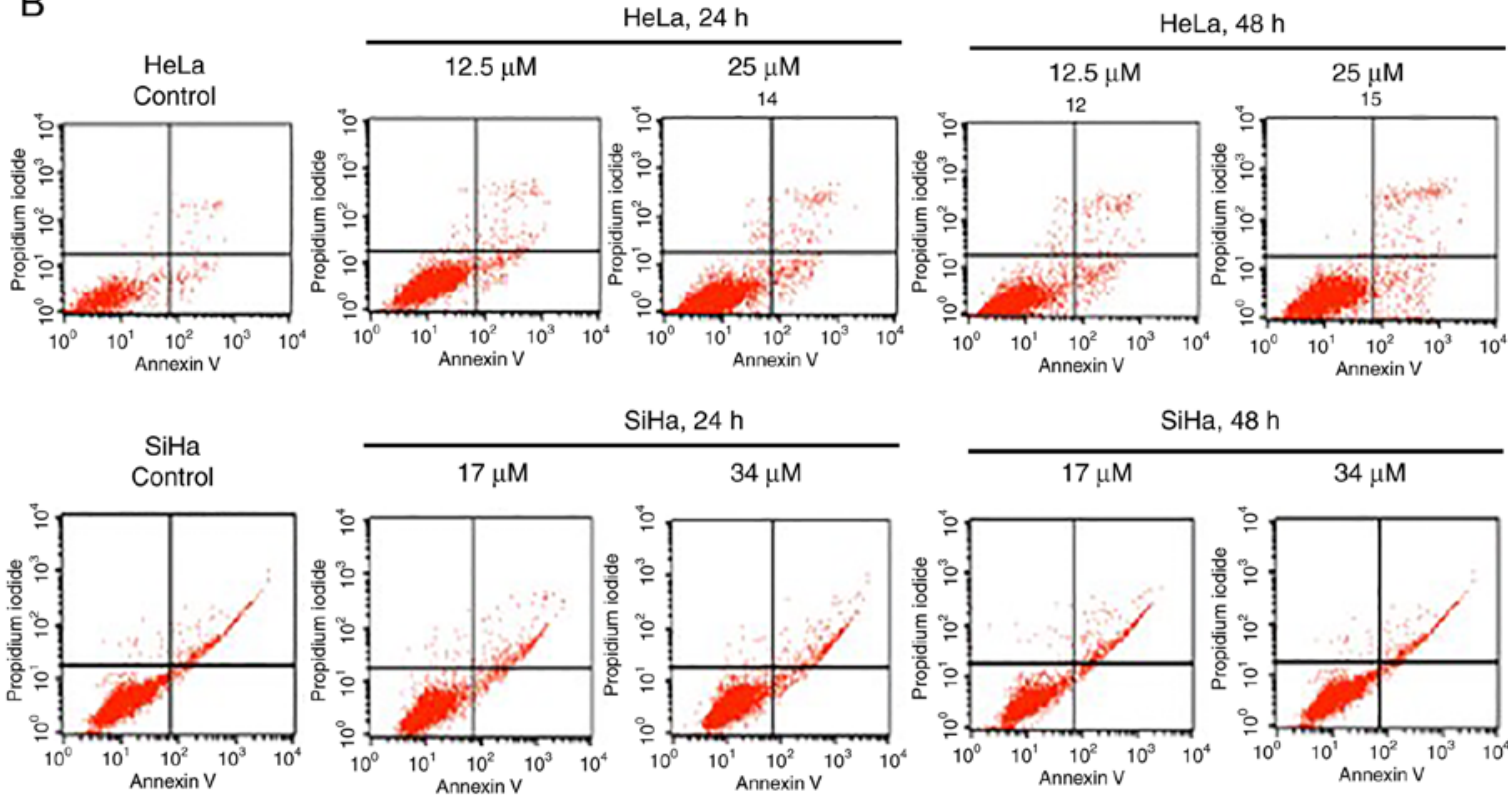

$\mathrm{SiHa}, 24 \mathrm{~h}$

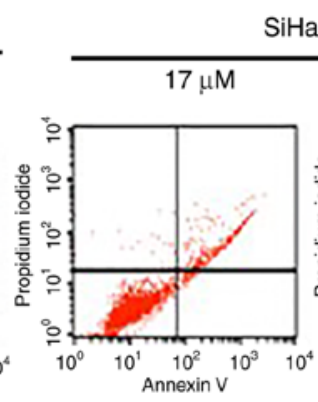

$\mathrm{SiHa}, 48 \mathrm{~h}$
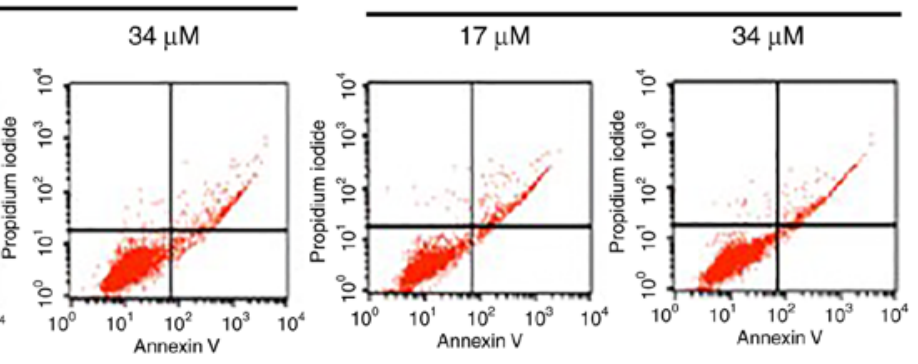

C
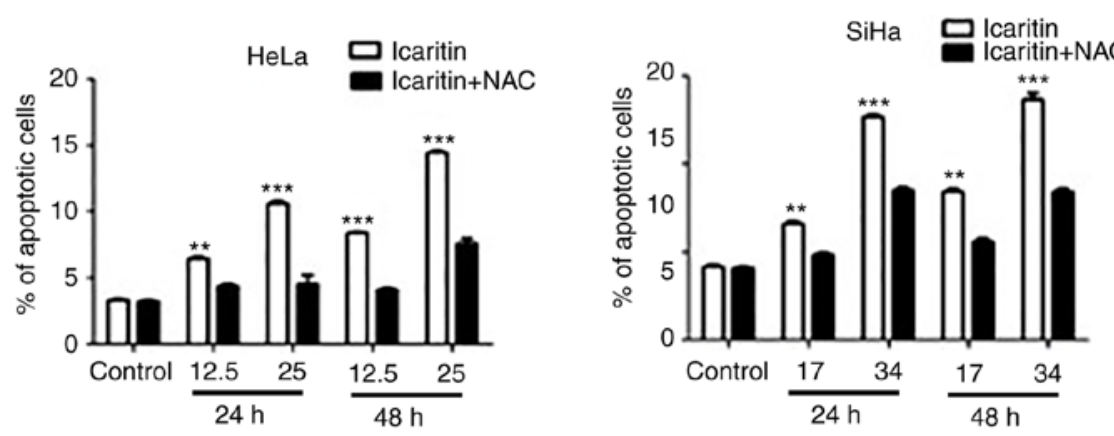

D

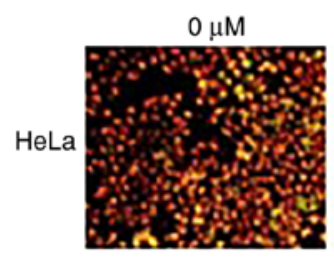

$12.5 \mu \mathrm{M}$

$25 \mu \mathrm{M}$
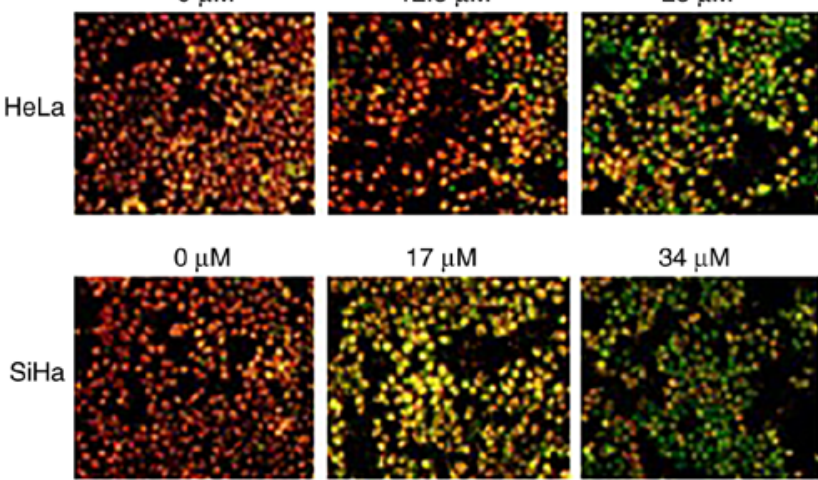

Figure 7. Analysis of apoptosis. (A) Representative images of nuclei stained with DAPI. HeLa cells were treated with $1 \mathrm{x} \mathrm{IC}_{50}$ or $2 \mathrm{x} \mathrm{IC}_{50} \mathrm{icaritin}_{\mathrm{for}} 24 \mathrm{~h}$ (arrows point to nuclei of apoptotic cells). (B) Analysis of Annexin V-fluorescein isothiocyanate and propidium iodide-stained cells by flow cytometry. HeLa or SiHa cells were treated by $1 \times \mathrm{IC}_{50}$ or $2 \mathrm{x} \mathrm{IC}$ icaritin for $24 \mathrm{~h}$ or $48 \mathrm{~h}$. (C) Quantification of flow cytometry data from three independent experiments. HeLa or SiHa cells with or without pre-incubation ( $1 \mathrm{~h}$ ) with $5 \mathrm{mM} \mathrm{NAC}$ were treated with $1 \mathrm{x} \mathrm{IC}_{50}$ or $2 \mathrm{x} \mathrm{IC} \mathrm{IC}_{50}$ icaritin for $24 \mathrm{~h}$ or $48 \mathrm{~h}\left({ }^{* *} \mathrm{P}<0.01\right.$; $\left.{ }^{* * * *} \mathrm{P}<0.001\right)$. (D) Measurement of mitochondrial membrane potential by JC-1. HeLa or SiHa cells were treated by $1 \mathrm{x} \mathrm{IC} \mathrm{IC}_{50}$ or $2 \mathrm{x} \mathrm{IC} \mathrm{I}_{50}$ for $24 \mathrm{~h}$. $\mathrm{IC}_{50}$, half maximal inhibitory concentration. 
A
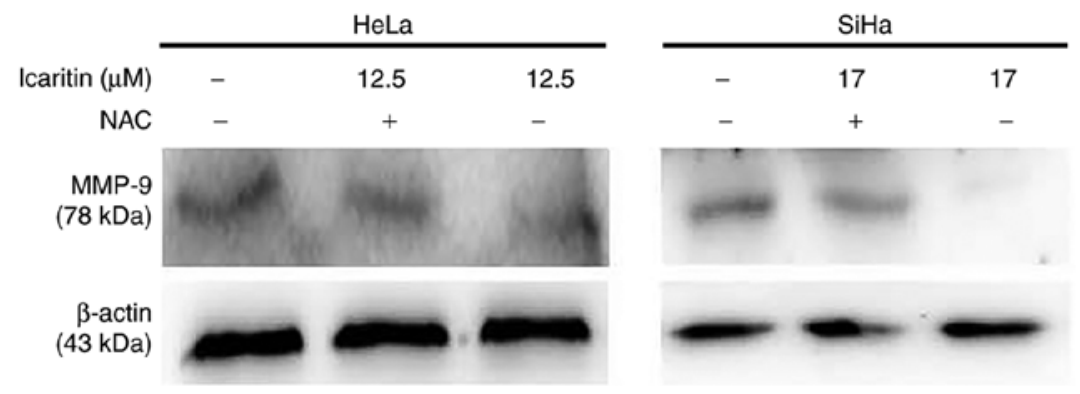

B
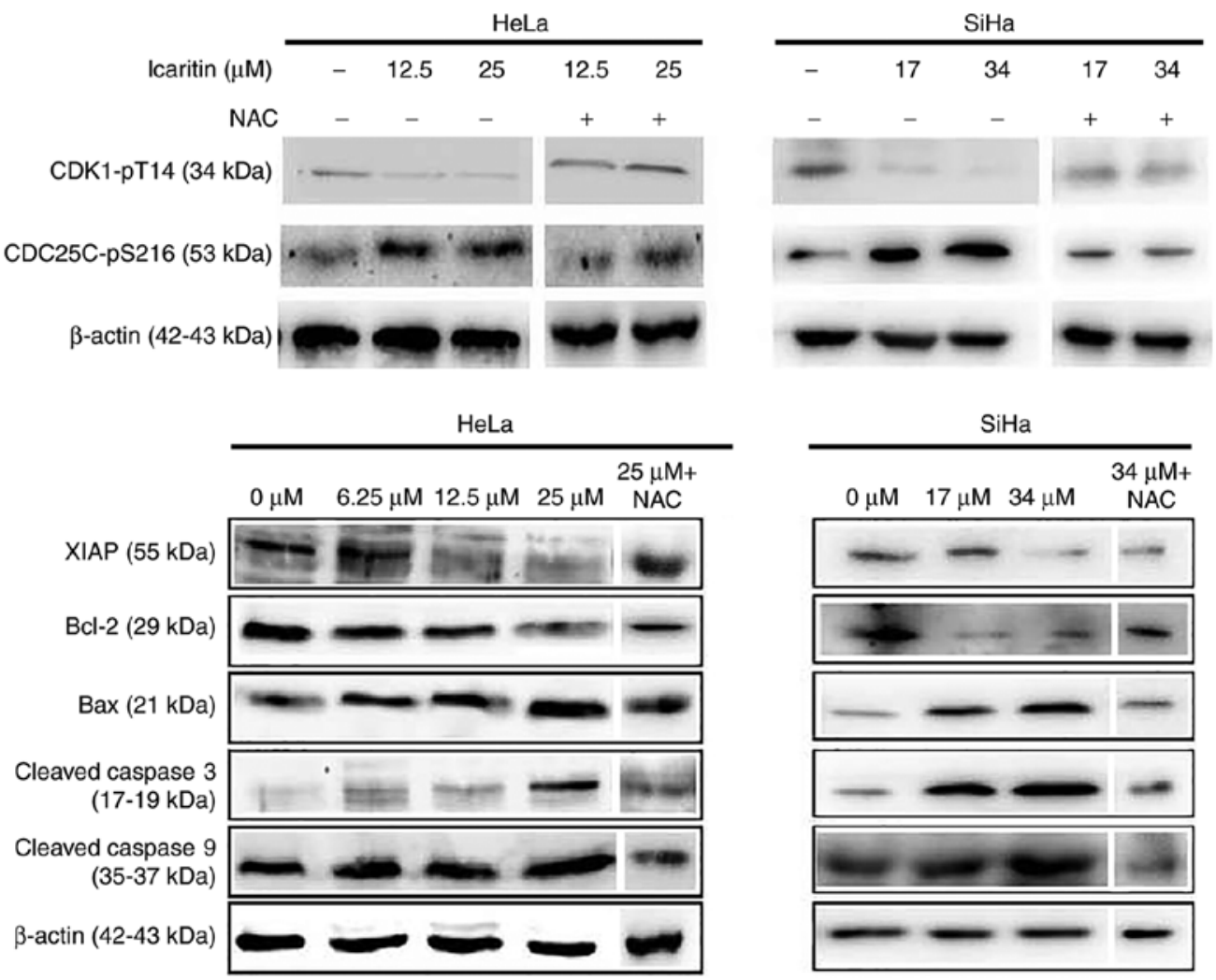

C
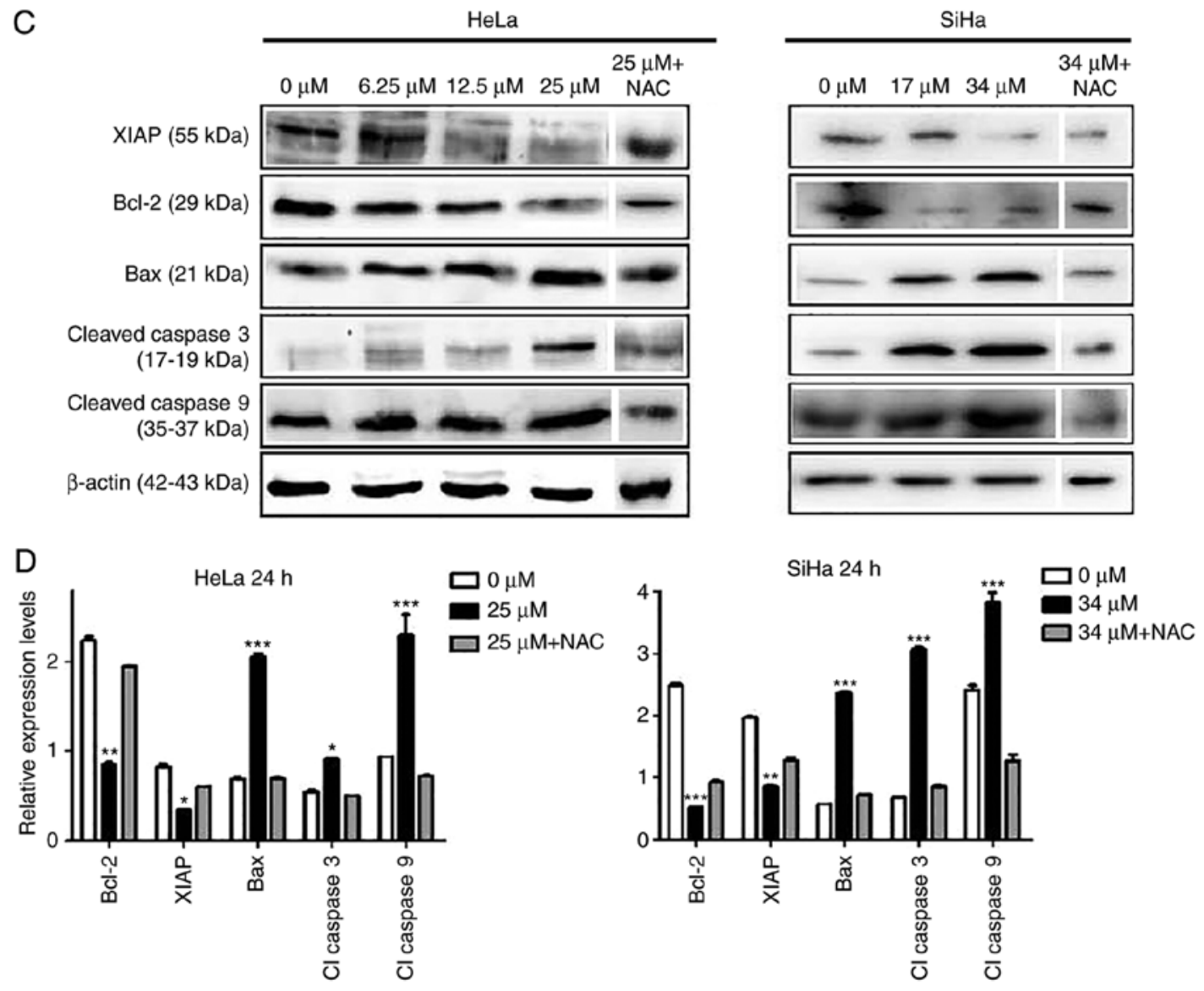

Figure 8. Western blot analysis. HeLa and SiHa cells with or without pre-incubation $(1 \mathrm{~h})$ with $5 \mu \mathrm{M} \mathrm{NAC}$ were treated by icaritin for $24 \mathrm{~h}$. Multiple SDS-PAGE gels were prepared for each sample, and each gel was used for the detection of one protein. Thus, one loading control, $\beta$-actin, was used for all proteins of each sample. (A) Detection of MMP-9. (B) Detection of cell cycle-associated proteins. (C) Detection of apoptosis-associated proteins. (D) Quantification of apoptosis-associated proteins in the $0 \mu \mathrm{M}, 2 \times \mathrm{IC}_{50}$ and $2 \mathrm{IC}_{50}+\mathrm{NAC}$ groups. Relative protein levels were quantified from western blots using ImageJ and presented as ratios of each protein band relative to the loading control. (" $\mathrm{P}<0.05,{ }^{* *} \mathrm{P}<0.01,{ }^{* * * *} \mathrm{P}<0.001$ vs. $\left.0 \mu \mathrm{M}\right)$. NAC, N-acetyl cysteine, MMP-9, matrix metalloproteinase-9; CDK1, cyclin-dependent kinase 1; CDC25C, cell division cycle 25C; XIAP, X-linked inhibitor of apoptosis protein; Bax, apoptosis regulator Bax; Bcl-2, B-cell lymphoma-2.

\section{Discussion}

In the present study, icaritin caused a potent suppression of the growth of HeLa and SiHa cervical cancer cells, although this effect was not observed for non-cancerous 293 epithelial and CCD-1095Sk fibroblast cells. Based on previous reports in the literature that demonstrated the cytotoxicity of this compound against a variety of cancer types $(11,26-28,31)$, the 
present study explored the hypothesis that icaritin possesses broad-spectrum anticancer activity. Icaritin is one of the major pharmaceutical components of the Epimedium family of plants (13), extracts of which have long been used in traditional Chinese herbal formulations (15). Studies have reported that icaritin possesses a variety of biological functions in a wide range of cell types. By inducing stem cell self-renewal (16) and osteogenic and cardiomyogenic differentiation, icaritin promotes repair of bone and cardiovascular injuries $(12,15)$. Icaritin has been shown to enhance osteoblastic differentiation and mineralization, inhibit bone resorption and induce apoptosis of osteoclasts (12). Animal studies indicate that icariin can prevent bone loss in ovariectomized rats and mice (12). A phase 1 clinical trial to determine the potential of icaritin treatment for osteoporosis and cardiovascular diseases is currently ongoing (trial no. NCT02931305). By inhibiting neuronal apoptosis, icaritin has neuroprotective effects against $\beta$-amyloid-induced neurotoxicity (17); and by acting as a highly selective ERa36 modulator, icaritin inhibited the growth of multiple types of cancer cells both in vitro and in vivo (11). Phase 1 and $1 \mathrm{~b}$ clinical trials to assess safety and efficacy of oral icaritin in advanced solid tumors have been completed (trial nos. NCT01278810 and NCT02496949); although the results have not been published, the fact that phase 2 and phase 3 clinical trials have been initiated (trial nos. NCT01972672, NCT03236636 and NCT03236649) indicates that the safety and efficacy of icaritin are encouraging. Thus, it appears that this compound may be a good candidate and/or may serve as a chemical scaffold for the development of novel anticancer drugs.

Previous studies have reported that icaritin can suppress various different types of cancer by induction of cell cycle arrest, apoptosis and/or autophagic cell death $(11,26,32,34)$. Several different, and sometimes contradictory, mechanisms have been proposed to explain its anticancer activity, including suppression of IL-6/Jak2/STAT3 or MAPK signaling (27-30), sustained activation of ERK1/2 and/or JNK1 $(26,31,32)$, inhibition of the PI3K/Akt pathway (33) and AMPK-dependent inhibition of mTOR (34). However, the exact way by which icaritin treatment affects these diverse signaling pathways remains unclear. The data reported in the present study demonstrated that treatment of HeLa and SiHa cervical cancer cells with icaritin resulted in an immediate increase in cellular ROS (within $3 \mathrm{~h}$ of icaritin treatment), which was immediately followed by a dramatic increase in DNA 8-oxo-dG levels, in the number of cells with numerous bright $\gamma \mathrm{H} 2 \mathrm{AX}$ and 53BP1 foci, and in the number of DNA strand breaks, as determined by the comet assay. These effects were not noted in the non-cancerous 293 and CCD-1095Sk cells (data not shown). The blockage of ROS elevation using the ROS inhibitor, NAC, decreased the expression of markers of oxidative DNA damage. Cell cycle arrest and apoptosis were not noted when cells were treated with icaritin for $12 \mathrm{~h}$, but were apparent following treatment with this compound for $24 \mathrm{~h}$. Thus, these studies suggested that an increase in ROS levels caused by icaritin resulted in a rapid increase in oxidative DNA damage, which likely stimulated base excision repair and generated a large number of SSBs. Rapid and large-scale increases in SSB can saturate cellular repair capacity, convert SSBs into numerous DSBs, and eventually result in DDR signaling which induces cell cycle arrest and apoptosis $(7,10)$.
Notably, icaritin was recently reported to activate the mitochondrial apoptotic pathway in human oral squamous cell carcinoma cells by downregulating the expression of the transcription factor Sp1 (43), which was also noted to be induced by the human ribosomal protein uL3 (rpL3) (44). rpL3 downregulates $\mathrm{Spl}$ to inhibit the expression and protein stability of cystathionine- $\beta$-synthase (CBS). This in turn promotes mitochondrial translocation of CBS to trigger the intrinsic apoptotic pathway in p53 mutant cancer cells $(44,45)$. Furthermore, rpL3 increases cellular ROS levels by controlling the cellular redox status (46). Thus, it is likely that icaritin activates the mitochondrial apoptotic pathway via multiple complex mechanisms.

\section{Acknowledgements}

Not applicable.

\section{Funding}

The present work was supported in part by grants from National Natural Science Foundation of China (grant nos. 81320108025 and 81472662) and Science and Technology Development Plan of Jilin Province (grant no. 20160204013YY).

\section{Availability of data and materials}

The datasets used and/or analyzed during the present study are available from the corresponding author on reasonable request.

\section{Authors' contributions}

$\mathrm{XC}$ performed the experiments, analyzed the results, and wrote the manuscript. LS and YH performed the experiments. FL conceived, designed and coordinated the study. All authors read and approved the final manuscript.

\section{Ethics approval and consent to participate}

Not applicable.

\section{Patient consent for publication}

Not applicable.

\section{Competing interests}

The authors declare that they have no competing interests.

\section{References}

1. Dancey JE, Bedard PL, Onetto $\mathrm{N}$ and Hudson TJ: The genetic basis for cancer treatment decisions. Cell 148: 409-420, 2012.

2. Block KI, Gyllenhaal C, Lowe L, Amedei A, Amin ARMR, Amin A, Aquilano K, Arbiser J, Arreola A, Arzumanyan A, et al: Designing a broad-spectrum integrative approach for cancer prevention and treatment. Semin Cancer Biol (35 Suppl): S276-S304, 2015.

3. $\mathrm{Hu} \mathrm{X}$ and Zhang $\mathrm{Z}$ : Understanding the genetic mechanisms of cancer drug resistance using genomic approaches. Trends Genet 32: 127-137, 2016.

4. Zecchini V and Frezza C: Metabolic synthetic lethality in cancer therapy. Biochim Biophys Acta 1858: 723-731, 2017. 
5. Fece de la Cruz F, Gapp BV and Nijman SM: Synthetic lethal vulnerabilities of cancer. Annu Rev Pharmacol Toxicol 55: 513-531, 2015.

6. Pavlova NN and Thompson CB: The emerging hallmarks of cancer metabolism. Cell Metab 23: 27-47, 2016.

7. Moloney JN and Cotter TG: ROS signalling in the biology of cancer. Semin Cell Dev Biol 80: 50-64, 2018

8. Schieber M and Chandel NS: ROS function in redox signaling and oxidative stress. Curr Biol 24: R453-R462, 2014

9. Rudd SG, Valerie NCK and Helleday T: Pathways controlling dNTP pools to maintain genome stability. DNA Repair 44: 193-204, 2016

10. Rai P, Onder TT, Young JJ, McFaline JL, Pang B, Dedon PC and Weinberg RA: Continuous elimination of oxidized nucleotides is necessary to prevent rapid onset of cellular senescence. Proc Nat Acad Sci USA 106: 169-174, 2009.

11. Huang X, Zhu D and Lou Y: A novel anticancer agent, icaritin, induced cell growth inhibition, $\mathrm{G}_{1}$ arrest and mitochondrial transmembrane potential drop in human prostate carcinoma PC-3 cells. Eur J Pharmacol 564: 26-36, 2007.

12. Indran IR, Liang RL, Min TE and Yong EL: Preclinical studies and clinical evaluation of compounds from the genus Epimedium for osteoporosis and bone health. Pharmacol Ther 162: 188-205, 2016.

13. Tan HL, Chan KG, Pusparajah P, Saokaew S, Duangjai A, Lee LH and Goh BH: Anti-cancer properties of the naturally occurring aphrodisiacs: Icariin and its derivatives. Front Pharmacol 7: 191, 2016.

14. Wang ZQ and Lou YJ: Proliferation-stimulating effects of icaritin and desmethylicaritin in MCF-7 cells. Eur J Pharmacol 504: $147-153,2004$

15. Zhu DY and Lou YJ: Inducible effects of icariin, icaritin, and desmethylicaritin on directional differentiation of embryonic stem cells into cardiomyocytes in vitro. Acta Pharmacol Sin 26 477-485, 2005.

16. Tsang WP, Zhang F, He Q, Cai W, Huang J, Chan WY, Shen Z and Wan C: Icaritin enhances mESC self-renewal through upregulating core pluripotency transcription factors mediated by ER $\alpha$.Sci Rep 7: 40894, 2017.

17. Wang Z, Zhang X, Wang H, Qi L and Lou Y: Neuroprotective effects of icaritin against beta amyloid-induced neurotoxicity in primary cultured rat neuronal cells via estrogen-dependent pathway. Neuroscience 145: 911-922, 2007.

18. Ma HR, Wang J, Chen YF, Chen H, Wang WS and Aisa HA Icariin and icaritin stimulate the proliferation of $\mathrm{SKBr} 3$ cells through the GPER1-mediated modulation of the EGFR-MAPK signaling pathway. Int J Mol Med 33: 1627-1634, 2014

19. Zhang XT, Kang LG, Ding L, Vranic S, Gatalica Z and Wang ZY: A positive feedback loop of ER- $\alpha 36 /$ EGFR promotes malignant growth of ER-negative breast cancer cells. Oncogene 30 : 770-780, 2010.

20. Omarjee S, Jacquemetton J, Poulard C, Rochel N, Dejaegere A, Chebaro Y, Treilleux I, Marangoni E, Corbo L and Romancer ML: The molecular mechanisms underlying the ER $\alpha-36$-mediated signaling in breast cancer. Oncogene 36: 2503-2514, 2017.

21. Thiebaut C, Chamard-Jovenin C, Chesnel A, Morel C, Djermoune EH, Boukhobza $\mathrm{T}$ and Dumond H: Mammary epithelial cell phenotype disruption in vitro and in vivo through ERalpha36 overexpression. PLoS One 12: e0173931, 2017.

22. Wang X, Zheng N, Dong J, Wang X, Liu L and Huang J: Estrogen receptor- $\alpha 36$ is involved in icaritin induced growth inhibition of triple-negative breast cancer cells. J Steroid Biochem Mol Biol 171: 318-327, 2017

23. Chen M, Turhan AG, Ding H, Lin Q, Meng K and Jiang X: Targeting BCR-ABL ${ }^{+}$stem/progenitor cells and BCR-ABL-T315I mutan cells by effective inhibition of the BCR-ABL-Tyr177-GRB2 complex. Oncotarget 8: 43662-43677, 2017.

24. Tiong CT, Chen C, Zhang SJ, Li J, Soshilov A, Denison MS, Lee LS, Tam VH, Wong SP, Xu HE, et al: A novel prenylflavone restricts breast cancer cell growth through AhR-mediated destabilization of ER $\alpha$ protein. Carcinogenesis 33: 1089-1097, 2012.

25. Sun F, Indran IR, Zhang ZW, Tan MH, Li Y, Lim ZL, Hua R, Yang C, Soon FF, Li J, et al: A novel prostate cancer therapeutic strategy using icaritin-activated arylhydrocarbon-receptor to co-target androgen receptor and its splice variants. Carcinogenesis 36: 757-768, 2015 .

26. He J, Wang Y, Duan F, Jiang H, Chen MF and Tang SY: Icaritin induces apoptosis of HepG2 cells via the JNK1 signaling pathway independent of the estrogen receptor. Planta Med 76: 1834-1839, 2010.

27. Zhu JF, Li ZJ, Zhang GS, Meng K, Kuang WY, Li J, Zhou XF, Li RJ, Peng HL, Dai CW, et al: Icaritin shows potent anti-leukemia activity on chronic myeloid leukemia in vitro and in vivo by regulating MAPK/ERK/JNK and JAK2/STAT3 /AKT signalings. PLoS One 6: e23720, 2011.
28. Yang JG, Lu R, Ye XJ, Zhang J, Tan YQ and Zhou G: Icaritin reduces oral squamous cell carcinoma progression via the inhibition of STAT3 signaling. Int J Mol Sci 18: E132, 2017.

29. Li S, Priceman SJ, Xin H, Zhang W, Deng J, Liu Y, Huang J, Zhu W, Chen M, Hu W, et al: Icaritin inhibits JAK/STAT3 signaling and growth of renal cell carcinoma. PLoS One 8: e81657, 2013

30. Zhu S, Wang Z, Li Z, Peng H, Luo Y, Deng M, Li R, Dai C, Xu Y, Liu $S$, et al: Icaritin suppresses multiple myeloma, by inhibiting IL-6/JAK2/STAT3. Oncotarget 6: 10460-10472, 2015.

31. Guo Y, Zhang X, Meng J and Wang ZY: An anticancer agent icaritin induces sustained activation of the extracellular signal-regulated kinase (ERK) pathway and inhibits growth of breast cancer cells. Eur J Pharmacol 658: 114-122, 2011.

32. Tong JS, Zhang QH, Huang X, Fu XQ, Qi ST, Wang YP, Hou Y, Sheng J and Sun QY: Icaritin causes sustained ERK1/2 activation and induces apoptosis in human endometrial cancer cells. PLoS One 6: e16781, 2011

33. Li Q, Huai L, Zhang C, Wang C, Jia Y, Chen Y, Yu P, Wang H, Rao Q, Wang M, et al: Icaritin induces AML cell apoptosis via the MAPK/ERK and PI3K/AKT signal pathways. Int J Hematol 97: 617-623, 2013.

34. Li Z, Meng X and Jin L: Icaritin induces apoptotic and autophagic cell death in human glioblastoma cells. Am J Transl Res 8: 4628-4643, 2016.

35. Wo YB, Zhu DY, Hu Y, Wang ZQ, Liu J and Lou YJ: Reactive oxygen species involved in prenylflavonoids, icariin and icaritin, initiating cardiac differentiation of mouse embryonic stem cells. J Cell Biochem 103: 1536-1550, 2008.

36. Li C, Peng W, Song X, Wang Q and Wang W: Anticancer effect of icaritin inhibits cell growth of colon cancer through reactive oxygen species, Bcl-2 and cyclin D1/E signaling. Oncol Lett 12: $3537-3542,2016$

37. Song J, Shu L, Zhang Z, Tan X, Sun E, Jin X, Chen Y and Jia X: Reactive oxygen species-mediated mitochondrial pathway is involved in Baohuoside I-induced apoptosis in human non-small cell lung cancer. Chem Biol Interact 199: 9-17, 2012.

38. Zheng Q, Liu WW, Li B, Chen HJ, Zhu WS, Yang GX, Chen MJ and He GY: Anticancer effect of icaritin on human lung cancer cells through inducing $\mathrm{S}$ phase cell cycle arrest and apoptosis. J Huazhong Univ Sci Technol Med Sci 34: 497-503, 2014.

39. Musa J, Achenbach CJ, O'Dwyer LC, Evans CT, McHugh M, Hou L, Simon MA, Murphy RL and Jordan N: Effect of cervical cancer education and provider recommendation for screening on screening rates: A systematic review and meta-analysis. PLoS One 12: e0183924, 2017.

40. Ding Y, Wang H, Niu J, Luo M, Gou Y, Miao L, Zou Z and Cheng Y: Induction of ROS overload by alantolactone prompts oxidative DNA damage and apoptosis in colorectal cancer cells. Int J Mol Sci 17: 558, 2016.

41. Dong L, Wang H, Niu J, Zou M, Wu N, Yu D, Wang Y and Zou Z: Echinacoside induces apoptotic cancer cell death by inhibiting the nucleotide pool sanitizing enzyme MTH1. Onco Targets Ther 8: 3649-3664, 2015.

42. Yazinski SA and Zou L: Functions, regulation, and therapeutic implications of the ATR checkpoint pathway. Annu Rev Genet 50: 155-173, 2016.

43. Jin L, Miao J, Liu Y, Li X, Jie Y, Niu Q and Han X: Icaritin induces mitochondrial apoptosis by up-regulating miR-124 in human oral squamous cell carcinoma cells. Biomed Pharmacother 85: 287-295, 2017.

44. Pagliara V, Saide A, Mitidieri E, d'Emmanuele di Villa Bianca R, Sorrentino R, Russo G and Russo A: 5-FU targets rpL3 to induce mitochondrial apoptosis via cystathionine- $\beta$-synthase in colon cancer cells lacking p53. Oncotarget 7: 50333-50348, 2016.

45. Russo A, Saide A, Cagliani R, Cantile M, Botti G and Russo G: rpL3 promotes the apoptosis of p53 mutated lung cancer cells by down-regulating $\mathrm{CBS}$ and $\mathrm{NF \kappa B}$ upon 5-FU treatment. Sci Rep 6: 38369, 2016.

46. Russo A, Saide A, Smaldone S, Faraonio R and Russo G: Role of uL3 in multidrug resistance in p53-mutated lung cancer cells. Int J Mol Sci 18: E547, 2017.

This work is licensed under a Creative Commons Attribution-NonCommercial-NoDerivatives 4.0 International (CC BY-NC-ND 4.0) License. 